\title{
Subantarctic Mode Water Formation, Destruction, and Export in the Eddy-Permitting Southern Ocean State Estimate
}

\author{
IVAna CerovečKi, Lynne D. TAlley, And Matthew R. MAZlofF \\ Scripps Institution of Oceanography, University of California, San Diego, La Jolla, California \\ Guillaume MAZE \\ Laboratoire de Physique des Océans, UMR 6523, Ifremer, CNRS, IRD, UBO, Plouzané, France
}

(Manuscript received 11 July 2012, in final form 12 December 2012)

\begin{abstract}
Subantarctic Mode Water (SAMW) is examined using the data-assimilating, eddy-permitting Southern Ocean State Estimate, for 2005 and 2006. Surface formation due to air-sea buoyancy flux is estimated using Walin analysis, and diapycnal mixing is diagnosed as the difference between surface formation and transport across $30^{\circ} \mathrm{S}$, accounting for volume change with time. Water in the density range $26.5<\sigma_{\theta}<27.1 \mathrm{~kg} \mathrm{~m}^{-3}$ that includes SAMW is exported northward in all three ocean sectors, with a net transport of $(18.2,17.1) \mathrm{Sv}(1 \mathrm{~Sv} \equiv$ $10^{6} \mathrm{~m}^{3} \mathrm{~s}^{-1}$; for years 2005, 2006); air-sea buoyancy fluxes form $(13.2,6.8) \mathrm{Sv}$, diapycnal mixing removes $(-14.5$, $-12.6) \mathrm{Sv}$, and there is a volume loss of $(-19.3,-22.9)$ Sv mostly occurring in the strongest SAMW formation locations. The most vigorous SAMW formation is in the Indian Ocean by air-sea buoyancy flux $(9.4,10.9) \mathrm{Sv}$, where it is partially destroyed by diapycnal mixing $(-6.6,-3.1)$ Sv. There is strong export to the Pacific, where SAMW is destroyed both by air-sea buoyancy flux $(-1.1,-4.6) \mathrm{Sv}$ and diapycnal mixing $(-5.6,-8.4) \mathrm{Sv}$. In the South Atlantic, SAMW is formed by air-sea buoyancy flux $(5.0,0.5) \mathrm{Sv}$ and is destroyed by diapycnal mixing $(-2.3,-1.1)$ Sv. Peaks in air-sea flux formation occur at the Southeast Indian and Southeast Pacific SAMWs (SEISAMWs, SEPSAMWs) densities. Formation over the broad SAMW circumpolar outcrop windows is largely from denser water, driven by differential freshwater gain, augmented or decreased by heating or cooling. In the SEISAMW and SEPSAMW source regions, however, formation is from lighter water, driven by differential heat loss.
\end{abstract}

\section{Introduction}

The Southern Ocean is a region of intense water mass transformation and formation, thus having a vital role in redistributing heat and freshwater in the global overturning circulation (Macdonald and Wunsch 1996; Sloyan and Rintoul 2001a,b; Talley et al. 2003; Talley 2008). A major component of the Southern Ocean overturning circulation consists of the northward export of Subantarctic Mode Water (SAMW) and Antarctic Intermediate Water (AAIW) (McCartney 1982; Rintoul 1991; Sloyan and Rintoul 2001b), which ventilates large areas of the lower thermocline in all three Southern Hemisphere

Corresponding author address: Ivana Cerovečki, Climate, Atmospheric Science and Physical Oceanography, Scripps Institution of Oceanography, UC San Diego, 9500 Gilman Dr., La Jolla, CA 92093-0230.

E-mail: icerovecki@ucsd.edu oceans (Schmitz 1996; Hanawa and Talley 2001). These water masses play a significant role in Southern Hemisphere heat and freshwater transport, and also importantly impact the oceanic sink for tracers including anthropogenic $\mathrm{CO}_{2}$ (Sabine et al. 2004) and chlorofluorocarbons (Willey et al. 2004).

SAMW and AAIW are formed by winter cooling of waters just to the north of the Subantarctic Front (SAF) and northward cross-frontal fluxes of Polar Zone surface water, which give rise to vertical convection on the equatorward flank of the SAF, the northernmost core of the Antarctic Circumpolar Current (ACC), resulting in deep winter mixed layers that dominate subtropical gyre ventilation to the north. McCartney $(1977,1982)$ was the first to describe and name these thick winter mixed layers. The associated winter mixed layer depths range from 200 to $300 \mathrm{~m}$ in the Atlantic and western Indian Ocean to more than $500 \mathrm{~m}$ in the southeast Indian and Pacific Oceans (e.g., Dong et al. 2008). SAMW is the 
warmest in the western Atlantic $\left(15^{\circ} \mathrm{C}, 35.8 \mathrm{psu}\right.$, and 26.5 $\left.\sigma_{\theta}\right)$ where the SAF is farthest equatorward, and coldest just west of Drake Passage $\left(4^{\circ}-5^{\circ} \mathrm{C}, 34.2\right.$ psu, and 27.1 $\sigma_{\theta}$ ) where the SAF is farthest poleward. McCartney considered the densest SAMW in the southeastern $\mathrm{Pa}$ cific and Scotia Sea to be the principal precursor of AAIW, the low salinity water mass that fills the Southern Hemisphere subtropical gyres and the tropical oceans at $800-1000-\mathrm{m}$ depth (Hanawa and Talley 2001). This hypothesis was confirmed as part of an in situ study of SAMW and AAIW formation in the southeast Pacific in 2005/06 (Talley et al. 2006; Talley 2007; Holte 2010; Holte et al. 2012; Holte et al. 2013). This nearly point source of AAIW, with only minor modifications owing to mixing across the ACC at other longitudes, stands in contrast to the near circumpolar formation of SAMW (McCartney 1982; Rintoul et al. 2001).

Despite the fundamental importance of SAMW/AAIW for global ocean circulation and also for uptake of anthropogenic $\mathrm{CO}_{2}$ (Sabine et al. 2004), the relative roles of differing physical processes important for SAMW formation and destruction are still not completely understood (e.g., Naveira Garabato et al. 2003; Sloyan and Kamenkovich 2007). The complex mix of processes affecting the SAMW source in the winter mixed layer includes air-sea buoyancy fluxes, lateral circulation, Ekman and eddy-induced transport, and diapycnal mixing and upwelling (e.g., Sallee et al. 2010; Sloyan et al. 2010; Holte et al. 2012, 2013). These same processes, along with other biogeochemical phenomena, govern air-sea $\mathrm{CO}_{2}$ exchange. Using the highresolution $\left(1 / 6^{\circ} \times 1 / 6^{\circ}\right)$ Southern Ocean State Estimate (SOSE; Mazloff et al. 2010), recent advances have been made toward understanding the uptake and transport of anthropogenic $\mathrm{CO}_{2}$, highlighting the importance of SAMW formation in $\mathrm{CO}_{2}$ subduction (Ito et al. 2010). The same SOSE solution is used here to quantify the formation rate of SAMW and AAIW and export of these water masses northward out of the Southern Ocean.

Transformation of water from one density class to another is driven by air-sea buoyancy flux and diffusive processes (e.g., Tziperman 1986). The formation of water in each density class is given by the divergence of transformation with respect to density. Walin (1982) developed a method to estimate water mass formation due to air-sea heat flux, assuming that the error in ignoring diffusive diapycnal flux is no larger than the uncertainty in the air-sea heat flux estimates. Walin's method was subsequently applied by Speer and Tziperman (1992) and Speer et al. (1995) to estimate global-scale surface water mass formation rates from observations.
The Walin (1982) method has been extended to include the effects of diapycnal mixing using models (Garrett et al. 1995; Marshall et al. 1999; Nurser et al. 1999), and to estimate global average diapycnal diffusivities implied by global-scale transformation, using observations (Zhang and Talley 1998). Since diapycnal mixing is difficult to represent accurately in the models, and difficult to observe globally at all depths, its local role in water mass formation is still poorly quantified (e.g., Iudicone et al. 2008b; Sloyan and Kamenkovich 2007). Nevertheless, it has been shown that diapycnal mixing in the Southern Ocean cannot be neglected (e.g., Speer et al. 2000; Sloyan and Rintoul 2001a,b; Iudicone et al. 2008a,c) especially over rough topography (e.g., Heywood et al. 2002; Naveira Garabato et al. 2004, 2007), and is essential for water mass modification, especially when considering the very large spatial scales of the global overturning circulation. We here quantify the effects of diapycnal ocean mixing as the difference between the air-sea flux formation and the meridional transport of SAMW out of the Southern Ocean, accounting for the internal storage rate.

SOSE is particularly well suited to the problem of Southern Ocean water mass formation because of the following. (i) It is constrained to a large suite and number of oceanic observations, bringing SOSE oceanic fields close to the observations (Mazloff et al. 2010). The optimization procedure used in SOSE greatly reduces the misfit between its estimates of temperature and salinity and numerous observations (e.g., Argo profiling float data, the Southern Elephant Seals as Oceanographic Samplers project, hydrographic sections) thus yielding a much more accurate surface and interior density distribution (Mazloff et al. 2010). (ii) It has the full spatial and temporal resolution of a numerical model. (iii) It has internally and dynamically consistent oceanic fields and adjusted air-sea fluxes (evaluated in Cerovečki et al. 2011), so that they exactly satisfy the ocean circulation model equations. (iv) It is an eddy-permitting model that evolves rather than parameterizes eddy processes, which is especially important in the Southern Ocean where the meridional overturning circulation in the SAMW density range is believed to be a balance between the Eulerian mean flow and eddy-induced mean flow (e.g., Karsten and Marshall 2002) and is important given that many aspects of meridional overturning circulation differ in coarse and high-resolution models (Hallberg and Gnanadesikan 2006; Spence et al. 2009). Eddy effects are also important in water mass formation, as eddy buoyancy supply can be comparable in magnitude to buoyancy supply by air-sea fluxes (Cerovečki and Marshall 2008).

We are using SOSE iteration 22, which provides a state estimate for years 2005 and 2006, because Mazloff 
et al. (2010) has verified the high accuracy of its oceanic fields relative to observations. (More recent SOSE iterations include a longer time period, which are being used in subsequent work.)

In section 2 the SOSE setup, its adjusted air-sea buoyancy fluxes and sea surface density fields are presented, together with an outline of the methods. The spatial distribution and properties of SAMW and AAIW in the 2005/06 SOSE run are discussed in section 3. SAMW formation rates using Walin (1982) analysis with SOSE air-sea buoyancy fluxes and sea surface density are presented in section 4. For comparison, formation rates computed using other commonly-used air-sea buoyancy flux products appear in the Appendix. In section 5, the effects of diapycnal mixing on SAMW formation and destruction are diagnosed as the difference between the air-sea flux formation and the meridional transport of SAMW out of the Southern Ocean, accounting for the internal storage rate. Discussion and conclusions are provided in section 6 .

\section{Datasets and methods}

\section{a. Air-sea fluxes in SOSE}

The Southern Ocean State Estimate (Mazloff et al. 2010) provides a complete dataset including atmospheric forcing fields and three-dimensional oceanographic fields south of $24.7^{\circ} \mathrm{S}$ at $1 / 6^{\circ}$ horizontal resolution.

SOSE utilizes an adjoint model [four-dimensional variational data assimilation (4D-Var) method] to solve for the initial conditions and atmospheric state (air temperature, specific humidity, downwelling shortwave radiation, wind velocity, and precipitation) required to bring the ocean circulation model results into consistency with oceanic observations [see, for example, Stammer et al. (2004) or Wunsch and Heimbach (2007)]. The first-guess oceanic initial conditions are derived from and constrained to the $1^{\circ}$ resolution Ocean Comprehensible Atlas (OCCA) global state estimate (Forget 2010). The northern open boundary condition is also derived from OCCA. For the initial atmospheric state estimate, as well as constraints, SOSE uses the National Centers for Environmental Prediction-National Center for Atmospheric Research Reanalysis 1 (hereafter NCEP1) (Kalnay et al. 1996). As described in Mazloff et al. (2010), the adjusted atmospheric variables are combined with the Large and Pond (1981) bulk formulas to obtain the air-sea heat and freshwater flux forcing fields. This bulk formulation is used for historical reasons; the results are insensitive to this choice compared with more modern Coupled Ocean-Atmosphere Response Experiment (COARE) bulk formulas.
The SOSE net air-sea heat fluxes for 2005/06 are shown in Fig. 1. The most intense ocean heat loss is over the subtropical western boundary currents. The ocean also loses heat in the southernmost part of the Southern Ocean. The ocean gains heat over large regions of the subtropical gyres in the Pacific and Indian Oceans. Robust regions of large $\left(>50 \mathrm{~W} \mathrm{~m}^{-2}\right)$ ocean heat gain occur where cold polar waters flow northward beneath a more temperate atmosphere (e.g., Large and Yeager 2009, hereafter LY09), in the Malvinas Current east of Drake Passage, and east of New Zealand where the Subantarctic Front is steered northward. A significant band of heat gain that is unrelated to such northward flow is found in the Indian Ocean between the Subantarctic and Subtropical Fronts, between $40^{\circ}$ and $50^{\circ} \mathrm{S}$ and is also a feature of all of the other flux products compared here (Fig. 2).

To compare the air-sea heat flux and freshwater flux contributions to buoyancy flux, we convert freshwater and buoyancy fluxes to heat flux units of watts per squared meter (e.g., Moore and Renfrew 2002; Cerovečki et al. 2011). We express freshwater flux as the freshwater heat-equivalent flux defined by

$$
Q_{\mathrm{FW}}=-\rho_{0} \beta S c_{p}(E-P) / \alpha,
$$

where $\rho_{0}$ is a reference density, $S$ is salinity, $c_{p}$ is the specific heat for seawater, $E$ is evaporation $\left(\mathrm{m} \mathrm{s}^{-1}\right), P$ is precipitation $\left(\mathrm{m} \mathrm{s}^{-1}\right), \beta$ is the saline contraction coefficient, and $\alpha$ is the thermal expansion coefficient (as in Gill 1982), and positive flux results in increased buoyancy (decreased density) (opposite of Gill's convention). A heat flux contribution of $1 \mathrm{~W} \mathrm{~m}^{-2}$ to ocean buoyancy flux is equivalent to $1 \mathrm{mg}\left(\mathrm{m}^{2} \mathrm{~s}\right)^{-1}$ freshwater flux, or $\sim 3.1 \mathrm{~cm} \mathrm{yr}^{-1}$ of $E-P$ at $5^{\circ} \mathrm{C}$ (Large and Nurser 2001). The buoyancy heat-equivalent flux is the sum of the net air-sea heat flux and freshwater heat-equivalent flux. Positive heat/freshwater/buoyancy flux implies a decrease in surface density (an increase in surface buoyancy).

The SOSE freshwater heat-equivalent flux (Figs. 1c,d) shows net evaporation in the subtropical gyre and net precipitation in higher latitudes. The freshwater flux contribution to the buoyancy flux becomes increasingly important in higher latitudes owing to nonlinearity in the equation of state (Moore and Renfrew 2002). Thus, in the cold waters of the polar latitudes, the freshwater flux contribution is the same order as or larger than the heat flux contribution; the two reinforce each other in the broad heat gain regions of the ACC, while in regions of cooling, the freshwater and heat contributions to buoyancy flux may nearly cancel (Figs. 1e,f) (e.g., Warren et al. 1996; Speer et al. 2000). 

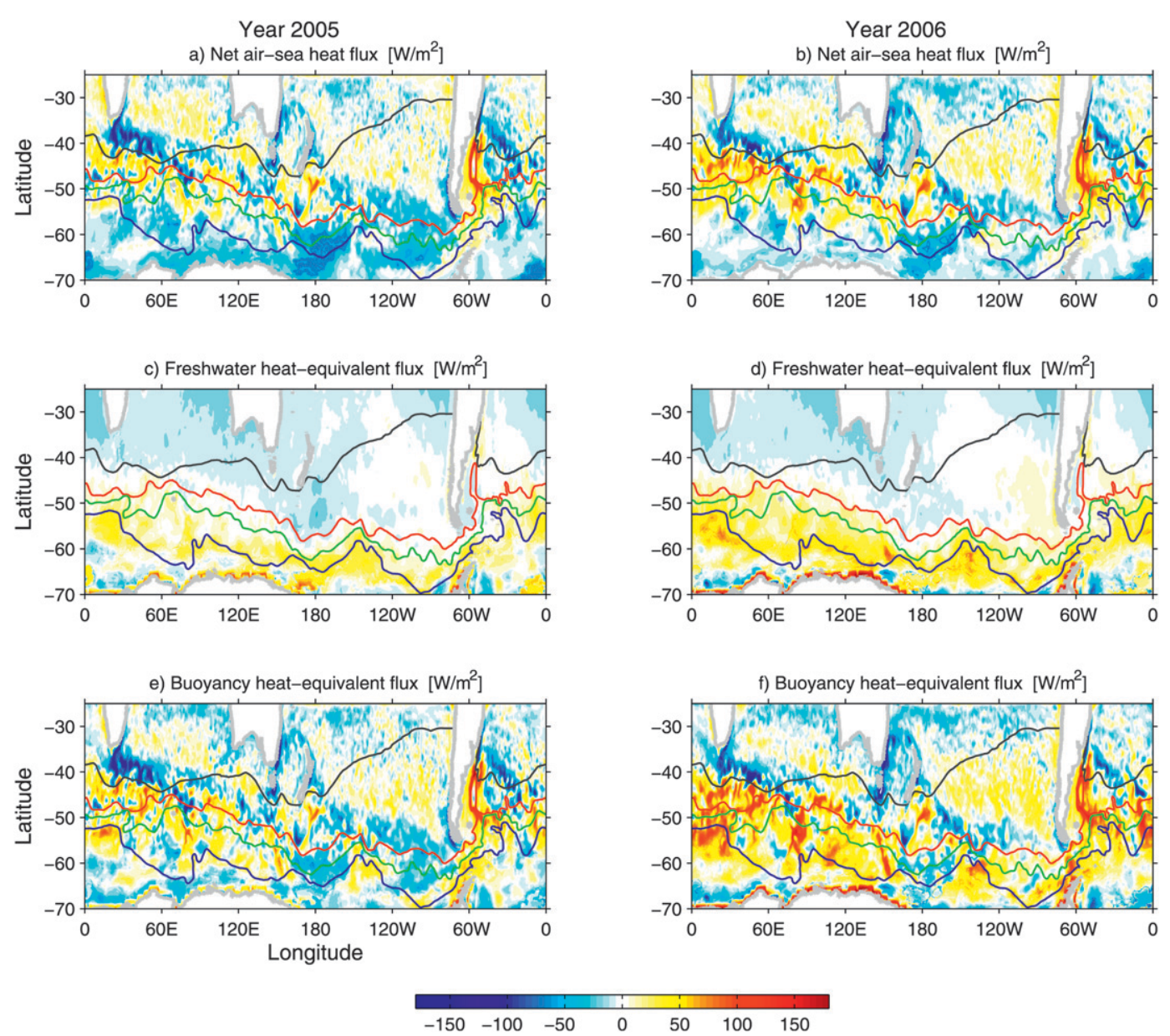

FIG. 1. (a),(b) SOSE air-sea heat flux, (c),(d) freshwater heat-equivalent flux from Eq. (1), and (e),(f) buoyancy heat-equivalent flux given by their sum, time averaged for years (left) 2005 and (right) 2006 ( $\mathrm{W} \mathrm{m}^{-2}$ ). Positive fluxes imply a decrease in surface density (increase in surface buoyancy). The color contours are climatological positions of the fronts given by Orsi et al. (1995): Subtropical Front (STF, black), SAF (red), Polar Front (PF, green), and Southern ACC front (SACC, blue).

Significant discrepancies between different air-sea buoyancy flux products are evident in Fig. 2 where the NCEP1 ocean buoyancy gain in polar latitudes (average for years 2005/06) is much stronger than in the European Centre for Medium-Range Weather Forecasts (ECMWF) Interim Re-Analysis (ERA-Interim), the LY09 flux product, and SOSE, whereas OCCA is characterized by ocean buoyancy loss rather than gain. These result in differing Walin formation rate estimates for the various flux products (see appendix), highlighting the importance of using air-sea fluxes that are consistent with the interior ocean properties, for example, SOSE.

\section{b. Formation rate estimates}

The density of a water parcel is predominantly changed at the sea surface through air-sea buoyancy fluxes, but it can also be changed in the interior through the usually weaker diapycnal fluxes associated with mixing. Surface SAMW formation in SOSE is estimated using the "Walin" approach (section 4). The SOSE velocity and density fields are then used to calculate net meridional export or import of water in isopycnal layers across $30^{\circ} \mathrm{S}$, zonal transports between the ocean basins, and the net storage rate in isopycnal layers during the 2-yr run (2005/06) (section 5). Finally, the formation rate due to diapycnal mixing is diagnosed as the difference between the surface formation and the sum of the export and interior storage rate (section 5c).

Our analysis is carried out only for densities lower than the densest variety of SAMW $\left(\sigma_{\theta}=27.1 \mathrm{~kg} \mathrm{~m}^{-3}\right)$ because the simplified sea ice model in this SOSE iteration reduces confidence in transports for higher densities that outcrop in the sea ice zone south of the Polar Front. Because of our cutoff at $\sigma_{\theta}=27.1 \mathrm{~kg} \mathrm{~m}^{-3}$, the 

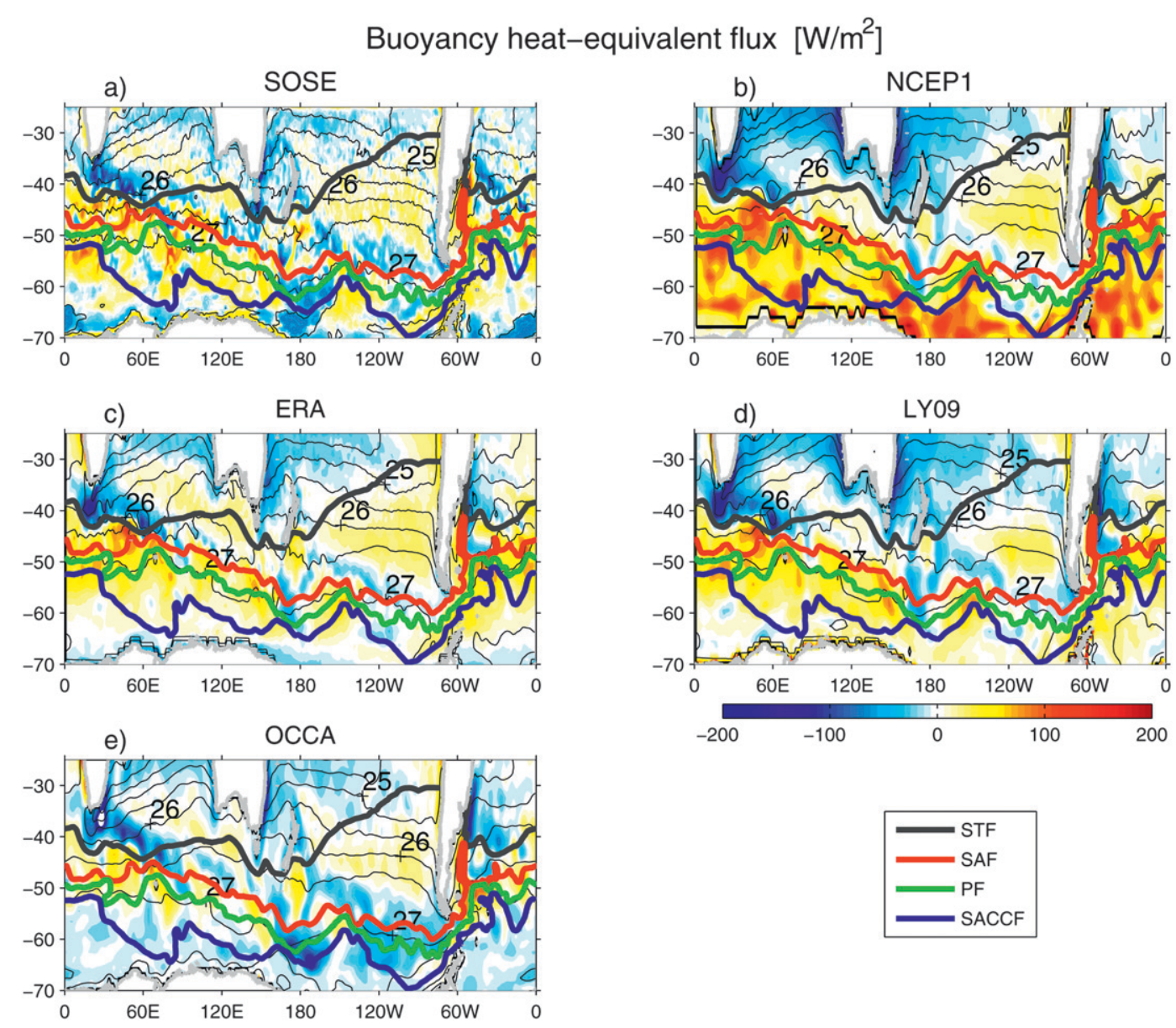

d)

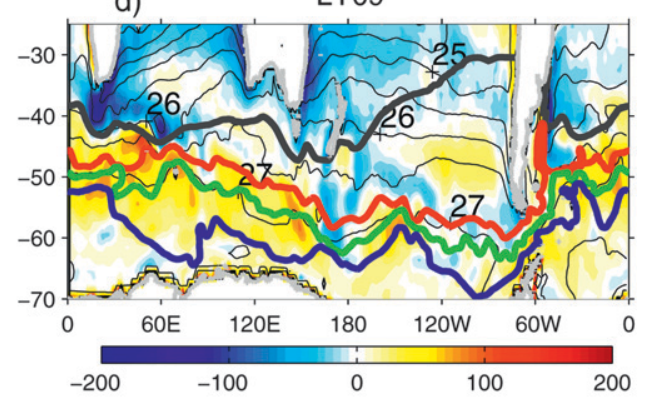

FIG. 2. Time-mean surface density ( $\sigma_{\theta}$ units, contours) and buoyancy heat-equivalent flux ( $\mathrm{W} \mathrm{m}^{-2}$, color shading), averaged for years 2005/06, obtained by (a) SOSE, (b) NCEP1, (c) ERA-Interim, (d) LY09, and (e) OCCA. Color contours are as in Fig. 1.

isopycnal layers are shallower than $\sim 1000 \mathrm{~m}$, and we can use potential density relative to the sea surface to approximate neutral surfaces.

\section{1) WALIN METHOD}

The Walin (1982) method quantifies the rate at which water is added to or destroyed within a specific density class. This "formation rate" is given by the divergence with respect to density of the "transformation rate," which is the rate at which water is transformed from one density class to another via a diapycnal volume flux $A$ either at the sea surface or in the interior of the ocean. In an inviscid, incompressible fluid, the transformation rate $A$ depends only on the nonadvective buoyancy supply to the volume considered, while the advective supply of buoyancy only deforms the bounding material surface without changing the volume. Following Garrett et al. (1995) and Marshall et al. (1999), the transformation rate $A$ is

$$
A=F(\sigma, t)-\frac{\partial D}{\partial \sigma}
$$

where $F(\sigma, t)$ is the net air-sea buoyancy flux integrated over the outcrop window bounded by isopycnal surfaces $\sigma \pm \Delta \sigma / 2$ (next subsection), and $D$ is the diapycnal buoyancy flux with diapycnal divergence $\partial D / \partial \sigma$. The water mass transformation rate $A$ has units cubic meters per second.

\section{2) Surface Formation RAte estimates}

The buoyancy flux $B$ is given by (e.g., Gill 1982)

$$
B=\frac{g}{\rho_{0}}\left[\frac{\alpha Q_{\mathrm{net}}}{c_{p}}-\rho_{0} \beta S(E-P)\right],
$$

where $Q_{\text {net }}$ is the net surface heat flux (positive for ocean heat gain). Positive buoyancy flux implies an increase in surface buoyancy (a decrease in surface density). (The 
sign convention is opposite that of Gill.) The associated transformation rate $F(\sigma, t)$ is the air-sea buoyancy flux integrated over the outcrop window bounded by isopycnal surfaces $\sigma \pm \Delta \sigma / 2$, given by

$$
F(\sigma, t)=\frac{\rho_{0}}{g \Delta \sigma} \iint_{\mathcal{A}_{S}(\sigma, t)} B \delta_{T}\left(\sigma^{\prime}, \Delta \sigma\right) d \mathcal{A}^{\prime},
$$

in which $\mathcal{A}^{\prime}(\sigma, t)$ is the instantaneous surface bounding the volume within which the density is $\sigma \pm \Delta \sigma / 2, \rho_{0}$ is the reference surface density, $g$ is gravitational acceleration, and $\delta_{T}\left(\sigma^{\prime}, \Delta \sigma\right)$ is a top-hat function of $\sigma^{\prime}$ which is zero except in the interval $\sigma \pm \Delta \sigma / 2$, where it has unit value (see, e.g., Speer and Tziperman 1992; Marshall et al. 1999). This equation holds for time dependent as well as steady flows (e.g., Marshall et al. 1999) because $\mathcal{A}^{\prime}$ is the instantaneous bounding surface. Positive $F$ corresponds to transformation toward increasing density.

The net water mass formation (destruction) rate $\mathcal{F} \mathcal{R}$ resulting from the air-sea buoyancy fluxes in the density layer $\sigma \pm \Delta \sigma / 2$ is obtained as the difference of the transformation rates at the two isopycnal surfaces bounding this isopycnal layer:

$$
\mathcal{F} \mathcal{R}=F\left(\sigma+\frac{\Delta \sigma}{2}\right)-F\left(\sigma-\frac{\Delta \sigma}{2}\right),
$$

where $\mathcal{F} \mathcal{R}$ also has units of cubic meters per second.

\section{3) FORMATION RATES BY DIAPYCNAL MIXING}

Calculation of water mass formation rates using airsea fluxes alone, following the Walin (1982) approach, ignores diapycnal processes [e.g., Equation (2)]. At the largest global spatial scales, the isopycnal layers are completely closed at the surface, and any net formation or destruction by air-sea fluxes at the sea surface must be balanced by diapycnal processes. Calculation of these rates yields a diagnosis of globally averaged diapycnal diffusivity for the given isopycnal (e.g., Zhang and Talley 1998). Because SOSE provides consistent airsea fluxes, velocity, and temperature/salinity fields, and includes the relevant diapycnal processes, we can estimate the effect of diapycnal processes by quantifying the proportion of SAMW that is formed (or destroyed) in the ocean interior, separate from air-sea fluxes. To do this, we calculate the volume transport between the Southern Ocean and the rest of the ocean across $30^{\circ} \mathrm{S}$ (section 5a), and the internal storage in isopycnal layers (section 5b), which is nonzero because the SOSE run is only two years and the system is not in steady state. The difference between the airsea flux formation rate and the export of water in a given density range corrected for internal storage is equal to the rate of gain or loss owing to diapycnal mixing (section 5c).

Volume transport $\mathcal{V}$ in isopycnal layers across a vertical section is calculated as

$$
\mathcal{V}\left(\sigma_{\theta} \pm \frac{\Delta \sigma}{2}\right)=-\iint_{\sigma_{\theta} \pm(\Delta \sigma / 2)} v d A
$$

where $\sigma_{\theta}$ is potential density anomaly referenced to the surface, $v$ is the velocity component perpendicular to the section, and $d A$ is the area of the vertical section bounded above and below by the isopycnals $\sigma_{\theta} \pm \Delta \sigma / 2$. Here, $\mathcal{V}$ has units of cubic meters per second. In our calculation the width of density bins $\Delta \sigma$ is $0.1 \mathrm{~kg} \mathrm{~m}^{-3}$. Both $v$ and $\sigma_{\theta}$ are five day averages of SOSE output.

The interior storage rate $\partial V\left[\sigma_{\theta} \pm(\Delta \sigma / 2), t\right] / \partial t$ for each of the two years is the change in volume $V$ of each isopycnal layer from the beginning to the end of each year of the SOSE simulation. Finally, the rate of formation or destruction due to the diapycnal mixing $\partial^{2} D\left[\sigma_{\theta} \pm(\Delta \sigma / 2)\right] / \partial \sigma^{2}$ [from Eqs. (2) and (5)] is estimated considering the volume budget of each density layer $\sigma_{\theta} \pm \Delta \sigma / 2$ :

$$
\frac{\partial V\left(\sigma_{\theta} \pm \frac{\Delta \sigma}{2}\right)}{\partial t}=\mathcal{V}\left(\sigma_{\theta} \pm \frac{\Delta \sigma}{2}\right)+\mathcal{F} \mathcal{R}+\mathcal{D} \mathcal{R},
$$

where $\partial V\left[\sigma_{\theta} \pm(\Delta \sigma / 2), t\right] / \partial t$ is the storage rate, $\mathcal{V}\left[\sigma_{\theta} \pm\right.$ $(\Delta \sigma / 2), t]$ is the volume transport in (or out of) the same isopycnal layer in the relevant ocean sector (meridionally across $30^{\circ} \mathrm{S}$ and zonally into and out of the ocean sector) [Eq. (6)], where positive (negative) transport is into (out of) the relevant ocean sector, and $\mathcal{F R}$ is formation by air-sea fluxes [Eq. (5)]. $\mathcal{D} \mathcal{R}$ is the diapycnal mixing equivalent to $\mathcal{F} \mathcal{R}$, and, from Eqs. (2) and (5), is given by

$$
\mathcal{D R}=\frac{\partial D}{\partial \sigma}\left(\sigma+\frac{\Delta \sigma}{2}\right)-\frac{\partial D}{\partial \sigma}\left(\sigma-\frac{\Delta \sigma}{2}\right) .
$$

Since the terms comprising $D$ have not been archived for the SOSE simulation analyzed here, we can calculate the net formation/removal rate $\mathcal{D} \mathcal{R}$ due to the diapycnal mixing from Eq. (8), but we cannot determine the dynamical source of the mixing (e.g., boundary layer dynamics, eddy stirring, wave breaking, wind mixing).

\section{SAMW spatial distribution and properties}

Before estimating the formation rates, we examine the distribution of SAMW (and AAIW) in SOSE. The high spatial resolution of SOSE provides much greater 
a) $\sigma=26.5$

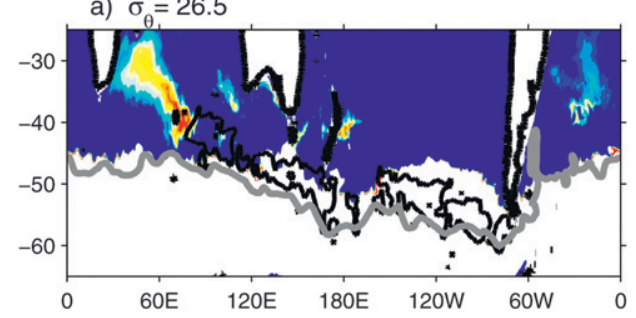

c) $\sigma_{\theta}=26.6$

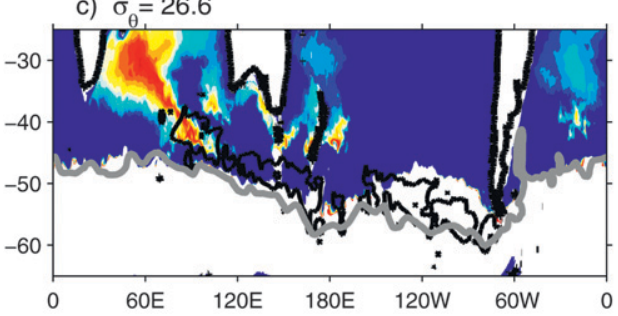

e) $\sigma=26.7$

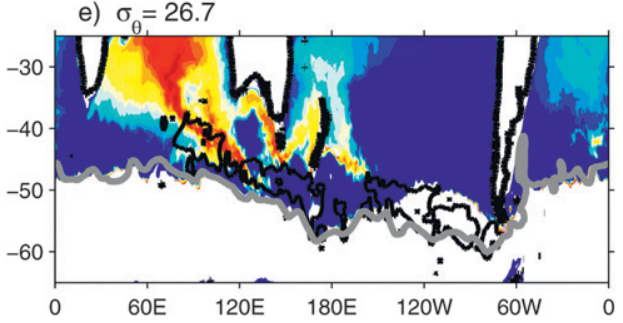

b) $\sigma=26.55$

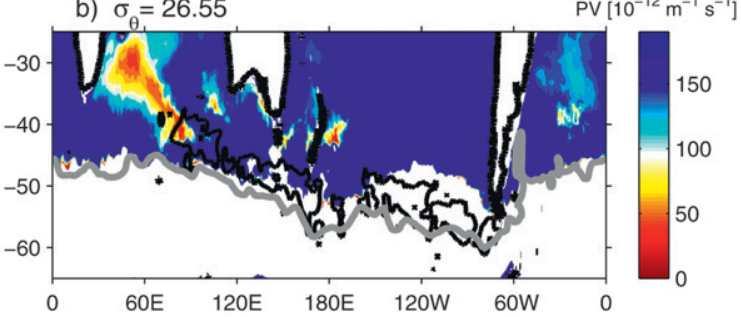

d) $\sigma_{\theta}=26.65$
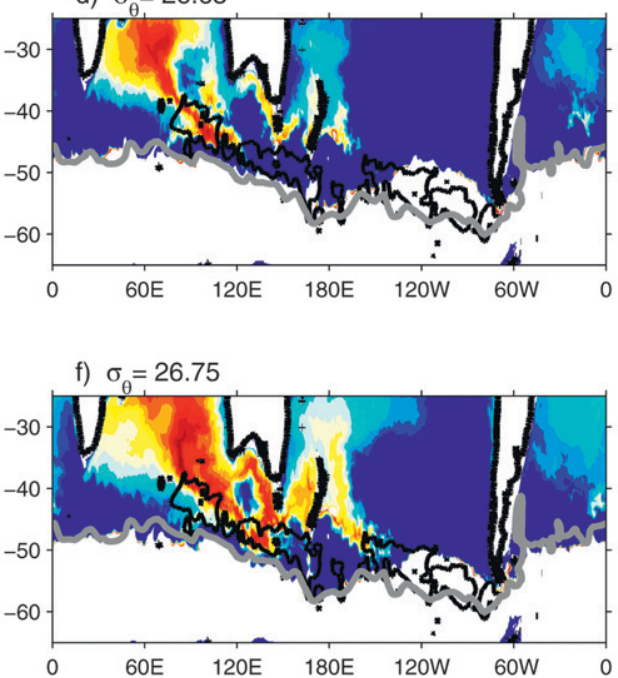

FIG. 3. Potential vorticity given by Eq. (9) $\left[10^{-12}(\mathrm{~m} \mathrm{~s})^{-1}\right]$, on constant $\sigma_{\theta}$ surfaces ranging from (a)-(f) 26.50 to 26.75 with the contour increment of 0.05 , averaged over years 2005 and 2006 from SOSE. Black line is the 300-m contour of September mixed layer depth from Dong et al. (2008). Thick gray line is the climatological position of the SAF given by Orsi et al. (1995).

detail than previously published maps based on hydrographic profile data; the bulk SAMW properties in SOSE are comparable to previously-published descriptions.

Mode water is a thick layer of nearly homogeneous water extending over a large area, usually situated between the seasonal and the main pycnoclines (e.g., Hanawa and Talley 2001). Because of its vertical homogeneity, mode water is characterized by low potential vorticity (PV). Neglecting relative vorticity, PV is

$$
\mathrm{PV}=\left(f / \rho_{\theta}\right) \partial \rho_{\theta} / \partial z
$$

where $f$ is the Coriolis parameter and $\rho_{\theta}=\sigma_{\theta}+$ $1000 \mathrm{~kg} \mathrm{~m}^{-3}$ is the potential density. The PV values that define the boundaries of specific mode waters in the literature are generally obtained empirically from observations. Following their eastward evolution along the ACC, we describe the Indian and then the Pacific Ocean SAMW distributions, and then briefly the South Atlantic's much weaker (relatively high PV) SAMW (e.g., McCartney 1982; Hanawa and Talley 2001).

\section{a. Indian Ocean}

Mode Water properties overall in the south Indian Ocean range from $\sigma_{\theta}=26.5$ to $26.9 \mathrm{~kg} \mathrm{~m}^{-3}$, including both Subtropical Mode Water and SAMW (Fine 1993; Wong 2005). Two major types of SAMW are identified: a lighter and less well-developed SAMW (relatively higher PV) in the west, with $\sigma_{\theta}=26.70 \mathrm{~kg} \mathrm{~m}^{-3}$, originating in the Subantarctic Zone between $70^{\circ}$ and $80^{\circ} \mathrm{E}$, and a stronger (lower PV) type of SAMW in the east, with $\sigma_{\theta}=26.85 \mathrm{~kg} \mathrm{~m}^{-3}$, originating in the Subantarctic Zone between $100^{\circ}$ and $110^{\circ} \mathrm{E}$ (McCartney 1982) (Figs. 3e and $4 \mathrm{~b}$ ). The denser SAMW is the southeast Indian SAMW (SEISAMW), which originates from especially deep mixed layers. After subduction it remains the most well developed and pervasive mode water in the Indian Ocean, and in fact is one of the dominant mode waters of the global ocean (e.g., McCarthy and Talley 1999; Hanawa and Talley 2001).

Deep winter mixed layers north of the Subantarctic Front, which are the source of SAMW, deepen toward the east in the Indian Ocean [evident in the Dong et al. 

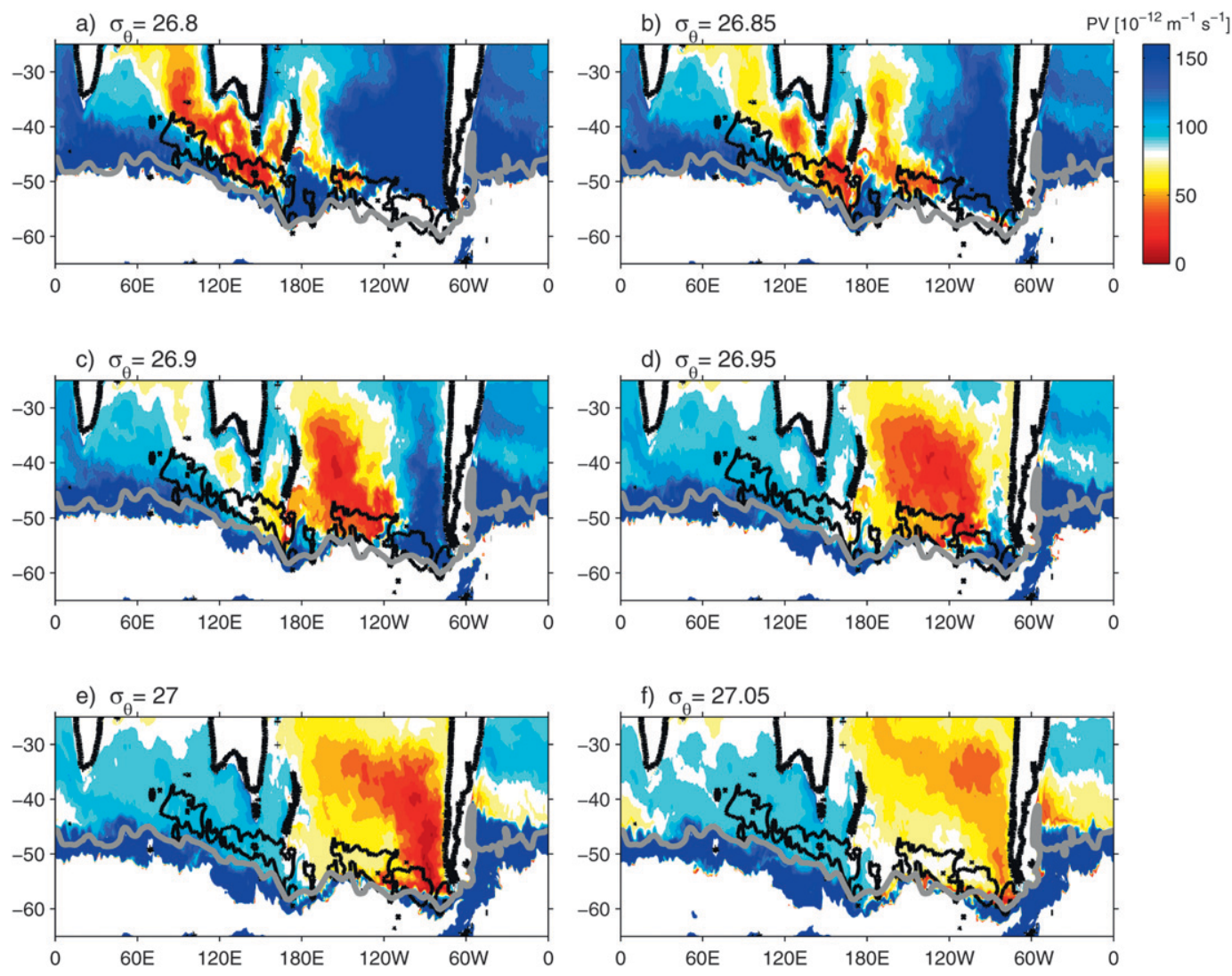

FIG. 4. As in Fig. 3, but showing $\sigma_{\theta}$ surfaces ranging from (a)-(f) 26.80 to 27.05 .

(2008) climatology superimposed in Figs. 3 and 4], with an especially large increase east of Kerguelen Plateau, becoming more than 500-550-m deep south of Tasmania. Using the $95 \%$ oxygen saturation depth as proxy for the mixed layer depths, Talley (1999) showed an abrupt onset of high oxygen and deep mixed layers in the central Indian Ocean east of Kerguelen Plateau, at $50^{\circ}-$ $60^{\circ} \mathrm{S}, 80^{\circ} \mathrm{E}$. Very low PV in the annual mean SOSE solution coincides with these very deep austral winter mixed layers (Figs. $3 f$ and $4 a$ ).

In SOSE the very low PV of SEISAMW is well depicted, as is the congruence between the location of lowest PV on the representative SEISAMW isopycnals $\sigma_{\theta}=26.75$ and $26.8 \mathrm{~kg} \mathrm{~m}^{-3}$ and the location of deep winter mixed layers north of the Subantarctic Front (from Dong et al. 2008) (Figs. 3f and 4a). The low PV distribution on the $\sigma_{\theta}=26.8$ surface closely resembles that shown in McCarthy and Talley (1999), with PV values of about $40 \times 10^{-12}(\mathrm{~m} \mathrm{~s})^{-1}$.

The SOSE representation of SEISAMW potential temperature and salinity (Fig. 5) is consistent with Thompson and Edwards (1981), Talley (1999), and Dong et al. (2008), among others. Thompson and Edwards (1981) observed winter formation of SEISAMW with potential temperature $8^{\circ}-9^{\circ} \mathrm{C}$, salinity 34.55 , and $\sigma_{\theta}=26.85 \mathrm{~kg} \mathrm{~m}^{-3}$. For comparison, at $\sigma_{\theta}=26.8$ and $26.9 \mathrm{~kg} \mathrm{~m}^{-3}$, SOSE potential temperature is $8^{\circ}-9^{\circ} \mathrm{C}$ and salinity is $34.6-34.7$.

\section{b. Pacific Ocean}

As originally described in McCartney (1977), SAMW density increases progressively eastward from the western Indian Ocean to the southeast Pacific Ocean, where the southeast Pacific SAMW (SEPSAMW) is formed (Figs. 4e,f from SOSE). SEPSAMW is the densest variety of SAMW. The lowest values of PV associated with the global distribution of SAMWs, less than $\sim 20 \times$ $10^{-12}(\mathrm{~m} \mathrm{~s})^{-1}$, are found in the southeast Pacific. Low PV values and deep winter mixed layers result from strong wintertime convection, which was observed directly in 2005 (e.g., Sloyan et al. 2010; Holte et al. 2012). McCartney (1977, 1982) and Piola and Georgi (1982) showed that SEPSAMW lies in the $\sigma_{\theta}$ range 27.05$27.1 \mathrm{~kg} \mathrm{~m}^{-3}$. In SOSE, the lowest PV, characteristic of SEPSAMW at $\sigma_{\theta}=27.0 \mathrm{~kg} \mathrm{~m}^{-3}$, lies west of the southwest corner of Chile and protrudes northwestward into the subtropical gyre (Figs. 4e,f), reflecting subduction and advection. 

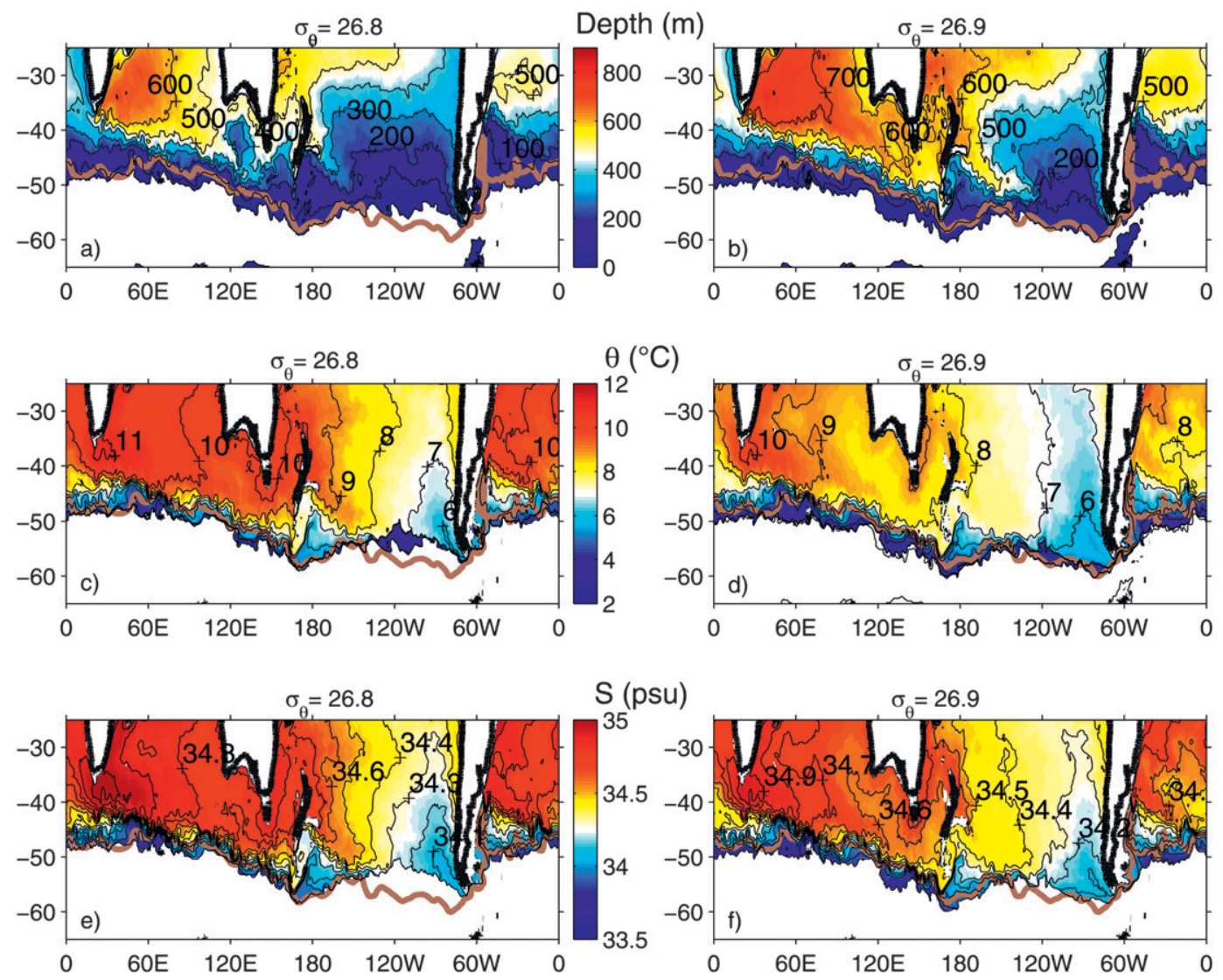

FIG. 5. (a),(b) Isopycnal distribution of depth (m), (c),(d) potential temperature $\left({ }^{\circ} \mathrm{C}\right)$, and (e),(f) salinity averaged over years 2005/06 from SOSE at: (left) $\sigma_{\theta}=26.8$ and (right) 26.9. Thick line is the climatological position of the SAF (Orsi et al. 1995).

On all isopycnals in Fig. 6, the lowest salinity is in the southeastern Pacific east of $\sim 120^{\circ} \mathrm{W}$, where PV is also lowest. The lowest PV is at $\sigma_{\theta}=27.0$ and $27.1 \mathrm{~kg} \mathrm{~m}^{-3}$, marking the SEPSAMW (Figs. 6e,f), which is the densest SAMW. Its potential temperature and salinity are $4^{\circ}-6^{\circ} \mathrm{C}$ and $34.0-34.3$, consistent with the $4^{\circ}-5^{\circ} \mathrm{C}$ and salinity of 34.2 summarized by Hanawa and Talley (2001). The associated isopycnal depths of 600-700 m agree with the inferred maximum depth of convection of more than $600 \mathrm{~m}$ in this region based on oxygen (Tsuchiya and Talley 1998); mixed layer depths of $550 \mathrm{~m}$ were observed directly in winter 2005 (Holte et al. 2012). This coldest, freshest, and densest SAMW is associated with AAIW (McCartney 1977), which is the vertical salinity minimum of the Southern Hemisphere. A portion of AAIW subducts northward into the South Pacific subtropical gyre and a portion of AAIW proceeds eastward into the Drake Passage (McCartney 1982; Talley 1996).

The eastward increase of SAMW density from the western Indian to the eastern South Pacific is also evident in vertical sections of $\mathrm{PV}$ at various latitudes (Fig. 7). The SEISAMW low PV pool at $\sigma_{\theta}=26.8 \mathrm{~kg} \mathrm{~m}^{-3}$ extends eastward from south of Australia to the central South Pacific, whereas the SEPSAMW low PV pool at $\sigma_{\theta}=27.0 \mathrm{~kg} \mathrm{~m}^{-3}$ is located west of Chile.

\section{c. Atlantic Ocean}

In comparison with the Indian and South Pacific, the South Atlantic forms only lighter mode waters, centered at $\sigma_{\theta}$ from 26.5 to $26.7 \mathrm{~kg} \mathrm{~m}^{-3}$ (Figs. 3b,c), and concentrated in the southwest; these have been considered to be either SAMW associated with the multiple fronts of the Malvinas-Brazil Current and the Subantarctic Front (McCartney 1977, 1982; Tsuchiya et al. 1994) or Subtropical Mode Waters associated with the Brazil Current (Provost et al. 1999). The South Atlantic mode waters are much weaker (higher PV) than the Indian or South Pacific SAMWs, as seen from the weaker low PV pool on these isopycnals (Figs. 3a-e).

The ridge of low PV in the Atlantic at $\sigma_{\theta}$ from 27.0 to $27.3 \mathrm{~kg} \mathrm{~m}^{-3}$ (Figs. 7b,c) is the SEPSAMW/AAIW from the southeastern Pacific, which is modified by air-sea buoyancy fluxes and mixing through the Drake Passage and the Malvinas Current. The result is a denser variety 

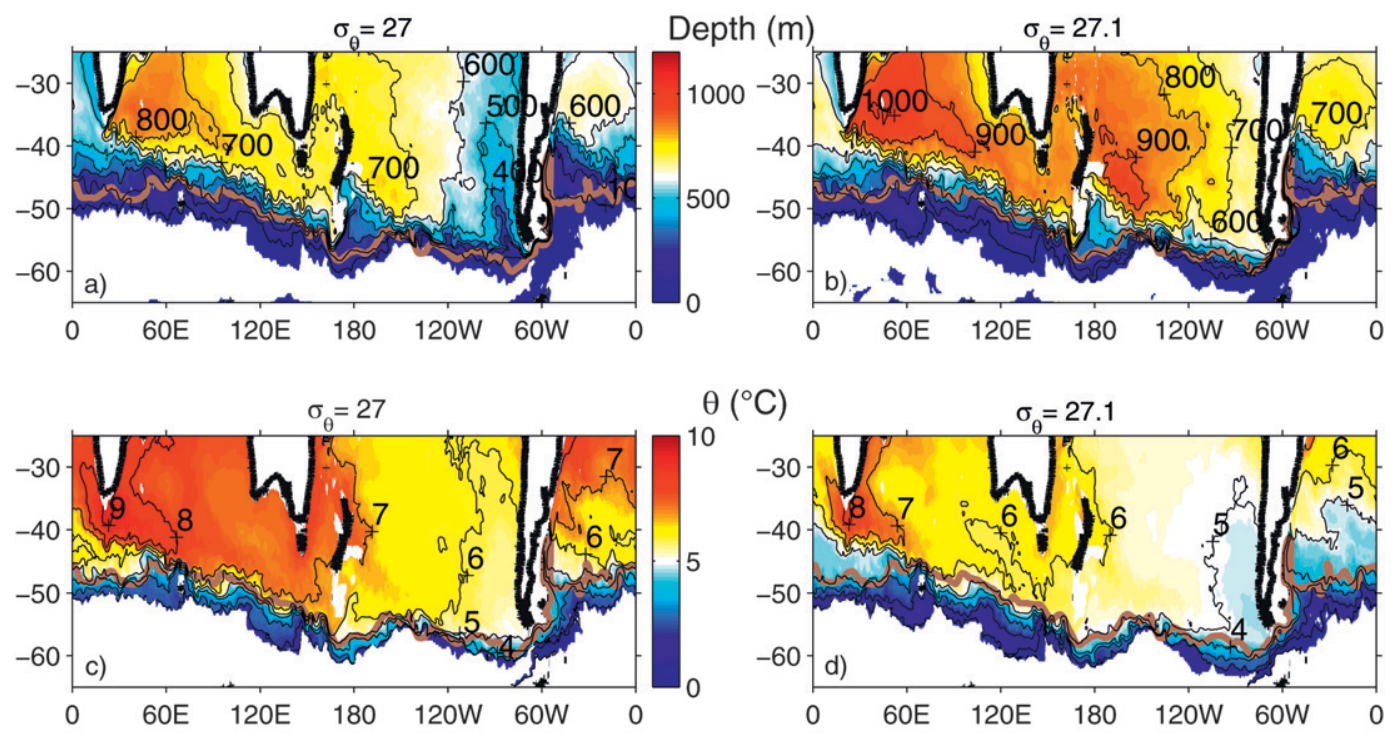

$\theta\left({ }^{\circ} \mathrm{C}\right)$
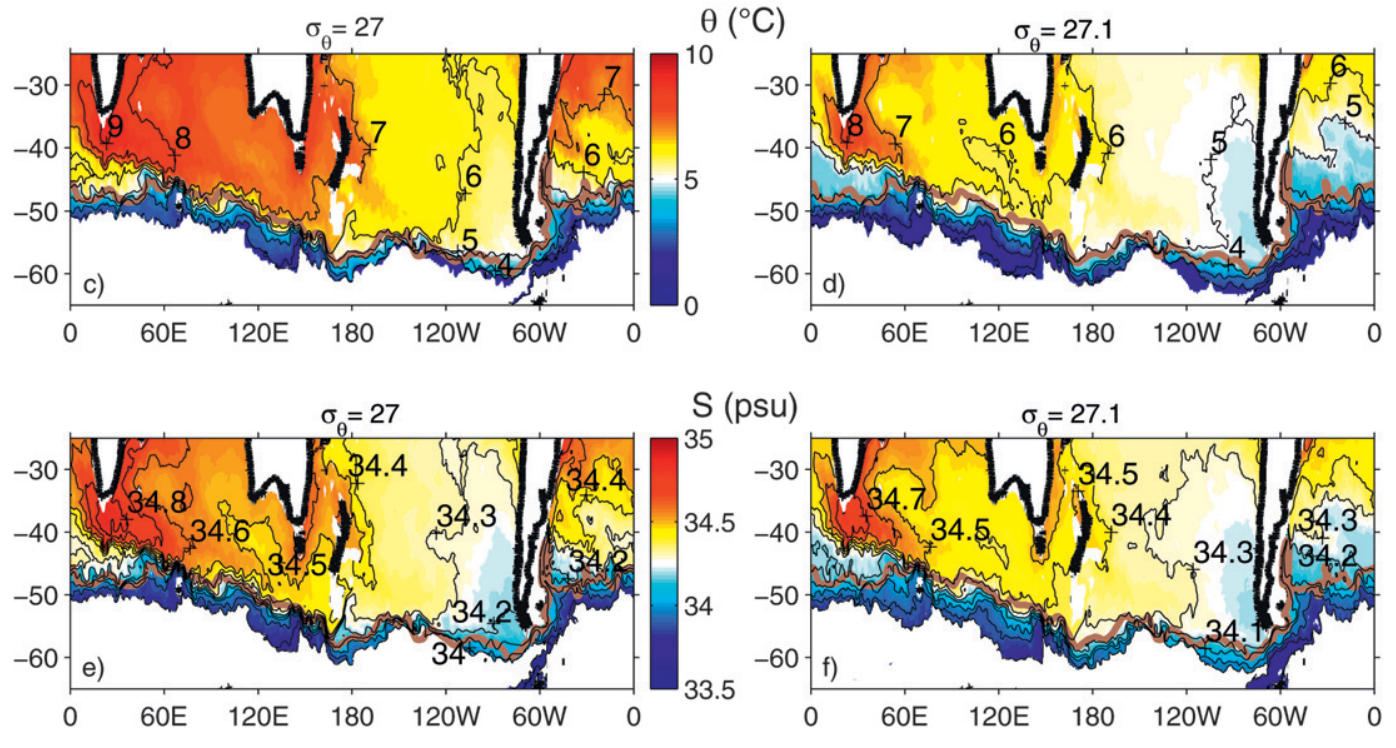

S (psu)

FIG. 6. As in Fig. 5, but for (left) $\sigma_{\theta}=27.0$ and (right) 27.1.

of AAIW in the Atlantic compared to the Pacific (e.g., Piola and Georgi 1982; Talley 1996), which is also evident in our Fig. 6f.

\section{SAMW transformation and formation by air-sea buoyancy fluxes}

To estimate global SAMW formation by air-sea buoyancy fluxes, we use the five-day-averaged air-sea buoyancy flux and sea surface density fields from SOSE (south of $24.7^{\circ} \mathrm{S}$, years $2005 / 06$, considering $\sigma_{\theta}<$ $27.1 \mathrm{~kg} \mathrm{~m}^{-3}$ ) as input in the Walin analysis (section 2). The buoyancy flux was integrated over the individual five-day averaged outcrop windows [Eq. (4)], with outcrop windows of width $\Delta \sigma=0.1 \mathrm{~kg} \mathrm{~m}^{-3}$. These five-dayaverage transformation rate estimates were subsequently averaged over one year. Formation rates were then calculated as the difference of the transformation rates at the two isopycnal surfaces bounding each isopycnal layer [Eq. (5)].

We first estimate global transformation and formation rates for the entire Southern Ocean (section 4a), considering the isopycnal outcrops that cover not only the deep mixed layer regions where the low PV SAMWs originate but also all of the remaining circumpolar regions. We refer to these global calculations as "formation in the SEISAMW/SEPSAMW density range." To diagnose regional processes, we second consider transformation and formation in individual ocean sectors, integrating the air-sea fluxes in each ocean, and adjusting the rates for the zonal transports between the ocean sectors within the isopycnal layers. Divisions between the oceans are taken at $150^{\circ} \mathrm{E}, 70^{\circ} \mathrm{W}$, and $20^{\circ} \mathrm{E}$. In both the global and regional estimates we consider isopycnal outcrop windows $0.1 \mathrm{~kg} \mathrm{~m}^{-3}$ wide, centered at the SEISAMW density $\left(26.75<\sigma_{\theta}<\right.$ $\left.26.85 \mathrm{~kg} \mathrm{~m}^{-3}\right)$, SEPSAMW density $\left(26.95<\sigma_{\theta}<\right.$ $27.05 \mathrm{~kg} \mathrm{~m}^{-3}$ ), and South Atlantic SAMW density $\left(26.45<\sigma_{\theta}<26.55 \mathrm{~kg} \mathrm{~m}^{-3}\right)$. Finally, to better describe the flux processes in the lowest PV/deepest mixed layer regions and which are therefore associated with SAMW formation per se, we describe the geographic distribution of transformation and formation using maps (section 4c). Throughout this section, we report formation rate estimates in pairs, for year 2005, followed by the estimate for year 2006. The associated uncertainty comes 


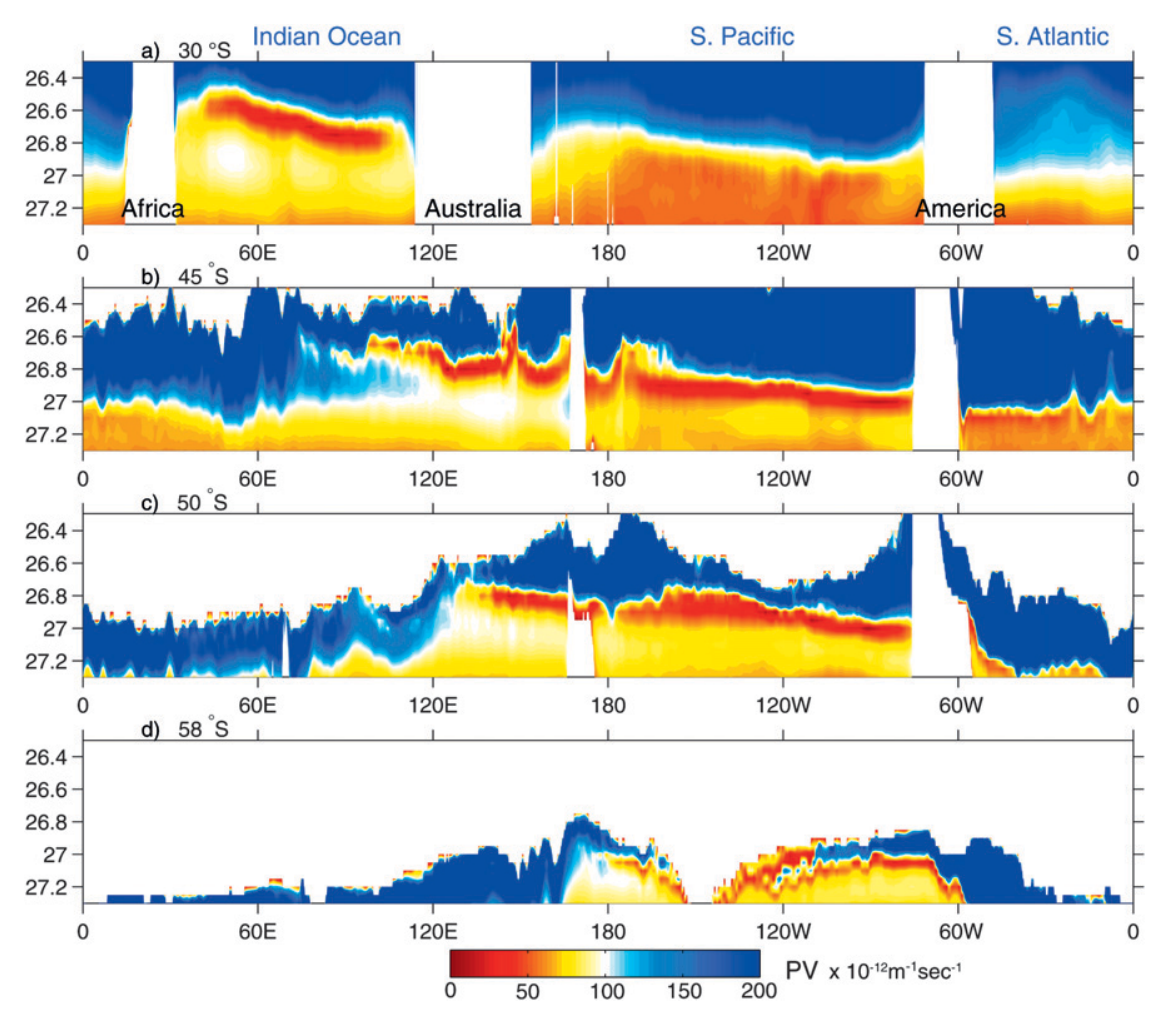

FIG. 7. Potential vorticity given by Eq. (9) along: (a) $30^{\circ} \mathrm{S}$, (b) $45^{\circ} \mathrm{S}$, (c) $50^{\circ} \mathrm{S}$, and (d) $58^{\circ} \mathrm{S}$ $\left[10^{-12}\left(\mathrm{~m} \mathrm{~s}^{-1}\right]\right.$.

primarily from errors in air-sea buoyancy flux fields, and to a lesser extent from biases in the sea surface density distribution. It was shown in Cerovečki et al. (2011) that SOSE estimates of air-sea buoyancy fluxes are within the range of the other commonly used air-sea buoyancy flux products, but since the air-sea buoyancy flux estimates in the Southern Ocean are poorly known (e.g., Bourassa et al. 2013), there is no "truth" to use as a reference for air-sea buoyancy fluxes (e.g., Taylor 2000). This renders it difficult to make quantitative error estimates.

\section{a. SAMW transformation and formation by surface heat and freshwater fluxes}

The most important feature of the annually averaged transformation rates is ocean buoyancy loss (becoming more dense, with positive transformation rates) at lower densities and buoyancy gain (becoming less dense with negative transformation rates) at the higher densities shown in Figs. 8a,c,e. At the lower densities, which outcrop in the subtropics, the net buoyancy loss was predominantly due to ocean heat loss, although net evaporation also contributed. In the SAMW density range $\left(26.5-27.1 \mathrm{~kg} \mathrm{~m}^{-3}\right)$, freshwater input (net precipitation) contributed to buoyancy gain in both years, but the heat flux changed sign: net heat loss in 2005, and net heat gain in 2006. As a result, in 2005, the ocean lost buoyancy at densities up into the SAMW range $\sigma_{\theta}<$ $26.85 \mathrm{~kg} \mathrm{~m}^{-3}$, while in 2006 ocean buoyancy loss was confined to densities lighter than $\sigma_{\theta}=26.1 \mathrm{~kg} \mathrm{~m}^{-3}$. In both years, freshwater gain was principally responsible for buoyancy gain at higher SAMW densities, although heat gain also contributed in 2006. This counterintuitive result, that even at these high latitudes buoyancy gain owing to both freshwater and heat gain is integral to global (circumpolar) transformation of water in the SAMW density range, has been described previously (Speer et al. 2000; Sloyan and Rintoul 2001a; Sallee et al. 2010).

Formation occurred in both years throughout the SAMW density range. The largest rates, at $\sigma_{\theta}=26.8$ and $27.0 \mathrm{~kg} \mathrm{~m}^{-3}$, correspond to SEISAMW and SEPSAMW (section 3) (Figs. 8b,d,f). There were also smaller formation peaks at $\sigma_{\theta}=26.5$ and $26.2 \mathrm{~kg} \mathrm{~m}^{-3}$, corresponding to South Atlantic SAMW and Subtropical Mode Water. Both freshwater fluxes and heat fluxes contributed to the formation. Because of monotonically larger freshwater gain with increasing density (i.e., farther poleward), differential freshwater input to the ocean contributed to formation throughout the SAMW density range. In 
a) Year 2005: Transformation (Sv)

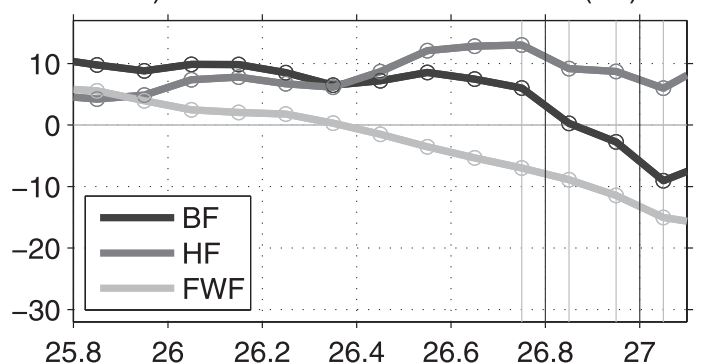

c) Year 2006: Transformation (Sv)

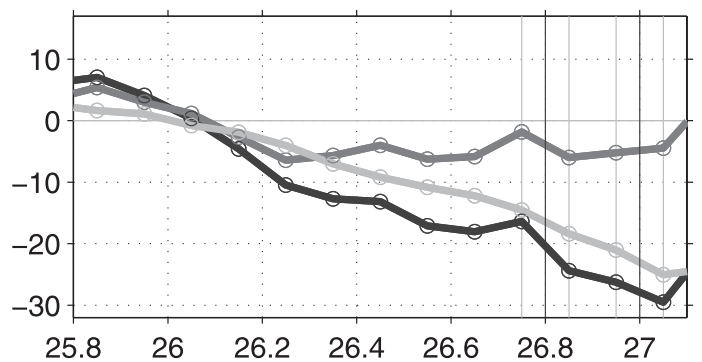

e) Time-average: Transformation (Sv)

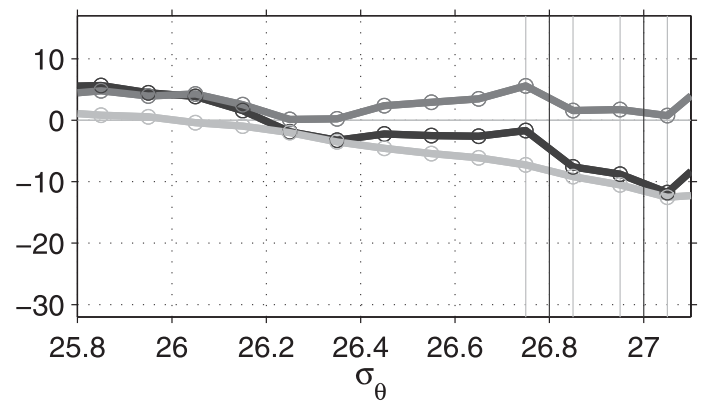

b) Formation (Sv)

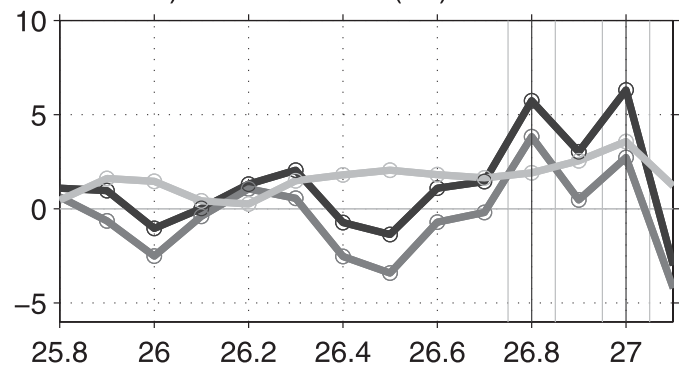

d) Formation (Sv)

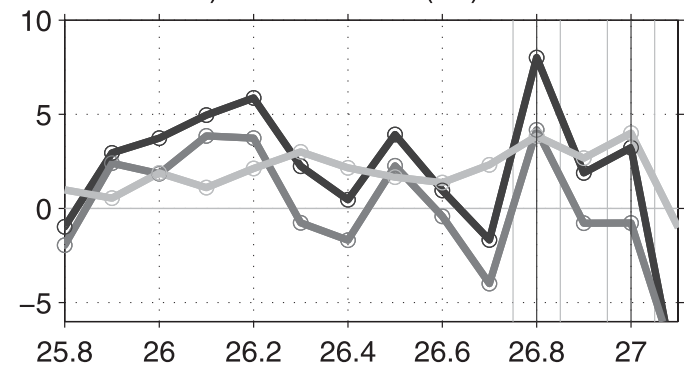

f) Formation (Sv)

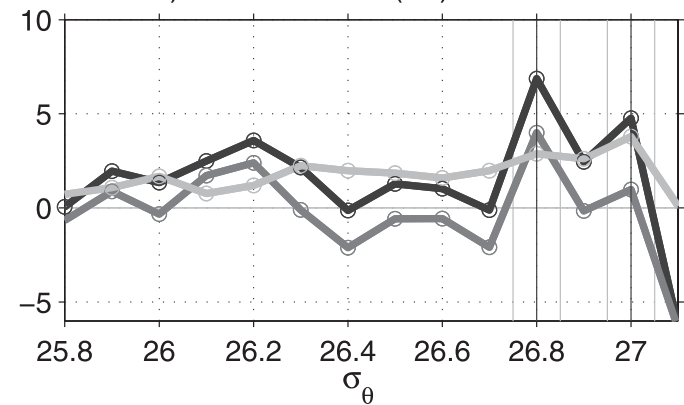

FIG. 8. The global ocean (south of $24.7^{\circ} \mathrm{S}$ ) (left) transformation and (right) formation rates ( $\mathrm{Sv}$ ) from five-day-averaged SOSE heat flux (HF-positive values correspond to ocean heat loss, ocean density increase), freshwater heat-equivalent flux (FWF-positive values correspond to freshwater loss by evaporation, ocean density increase), and buoyancy heatequivalent flux (shown in Fig. 1, BF) and sea surface density, subsequently averaged over years (top) 2005, (middle) 2006, and (bottom) 2005/06. A positive transformation rate corresponds to conversion of light water into denser water across a given isopycnal $\sigma_{\theta}$. Dark vertical lines mark the $\sigma_{\theta}$ values of southeast Indian SAMW (26.8) and southeast Pacific SAMW (27.0); light vertical lines show the limits of the corresponding outcrop windows, each $0.1 \sigma_{\theta}$ wide.

general, SAMW formation due to freshening was comparable in magnitude to SAMW formation (or destruction) because of heat flux.

\section{1) FORMATION IN THE SEISAMW DENSITY RANGE}

Globally the net formation by air-sea buoyancy fluxes for the narrow SEISAMW density range $\sigma_{\theta}=26.75-$ $26.85 \mathrm{~kg} \mathrm{~m}^{-3}$ was $(5.6,8.2) \mathrm{Sv}\left(1 \mathrm{~Sv} \equiv 10^{6} \mathrm{~m}^{3} \mathrm{~s}^{-1}\right.$; Fig. 8 and Table A1); the first number in parentheses is for 2005 and the second is for 2006, here and throughout. In both years, freshwater gain was stronger at higher densities so that more (denser) water was transformed into the SEISAMW range than was transformed out of the range, yielding $(1.8,4.0) \mathrm{Sv}$ of the total SEISAMW formation in $(2005,2006)$. Heat flux contributed to formation in both years, but for different reasons: in 2005, $3.8 \mathrm{~Sv}$ were formed from excess ocean heat loss of lighter waters relative to denser waters, and in 2006, $4.2 \mathrm{~Sv}$ were formed by excess ocean heat gain from denser waters relative to lighter waters.

Regionally, when Walin integration is performed only over the Indian Ocean sector with adjustment for isopycnal layer transport into and out of the sector, we still find that water in the SEISAMW density range was formed from denser water through buoyancy gain in both years. But within just the very lowest PV region indicating the source region of the true mode water, formation maps (section 4c) show that buoyancy loss (due to cooling) dominates the formation locally, in both 
a) Year 2005: Transformation (Sv)

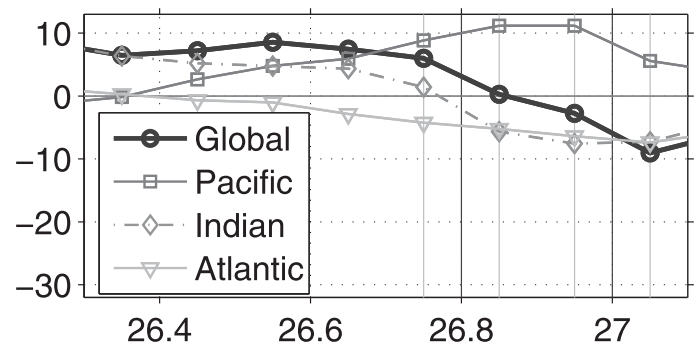

c) Year 2006: Transformation (Sv)

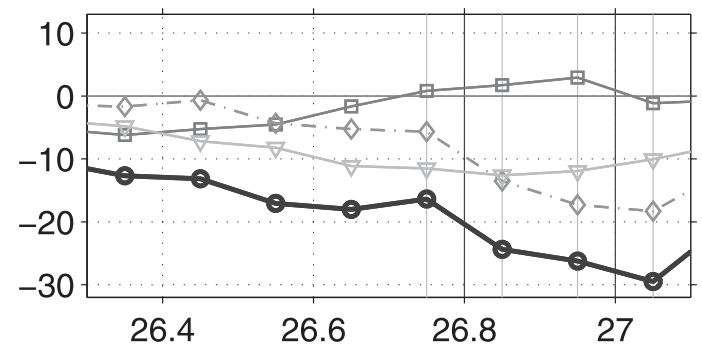

e) Time-average: Transformation (Sv)

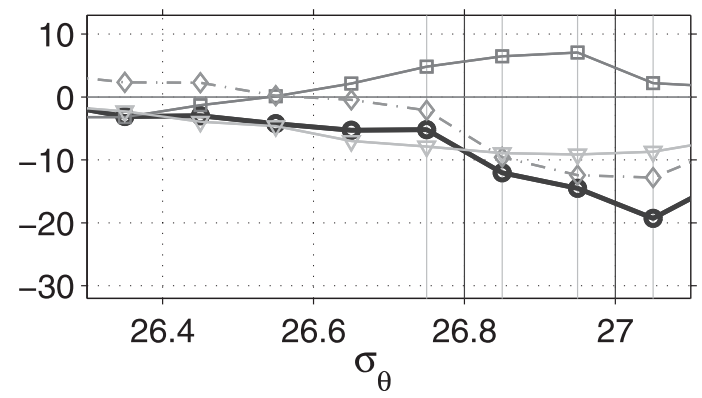

b) Formation (Sv)

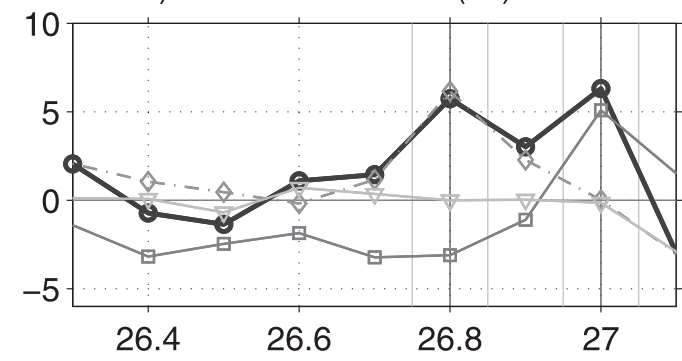

d) Formation (Sv)

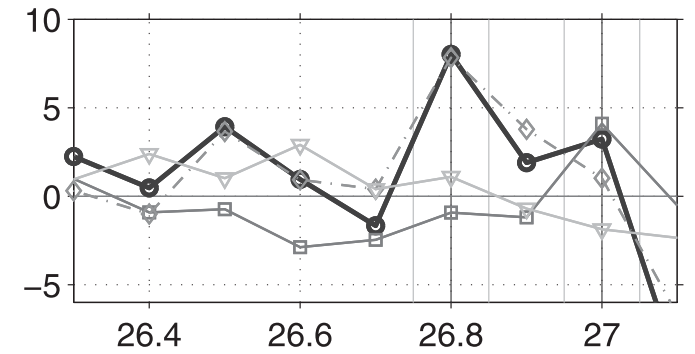

f) Formation (Sv)

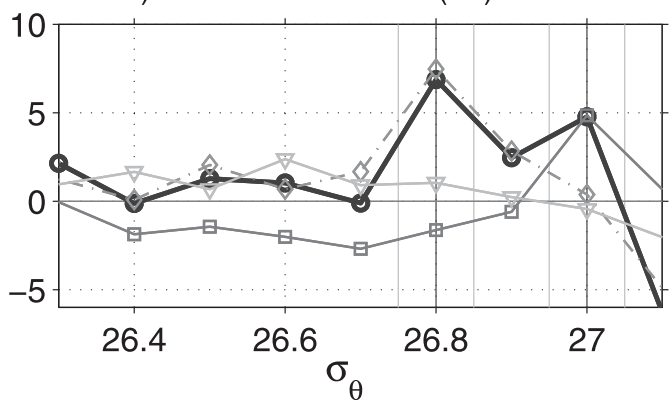

FIG. 9. (left) Transformation and (right) formation rates (Sv), using five-day-averaged SOSE buoyancy heatequivalent flux (whose annual average is shown in Fig. 1) and sea surface density for (top) 2005, (middle) 2006, and (bottom) average over both years, as in Fig. 8. Shown are the estimates for the global ocean south of $24.7^{\circ} \mathrm{S}$ as well as for the three individual ocean basins: Pacific, Indian, and Atlantic, where transports through the lateral sides of each ocean region in the uppermost layer of SOSE have been taken into account.

years. This comparison illustrates the high regional variablity emphasized, for example, by Sallee et al. (2010).

\section{2) FORMATION IN THE SEPSAMW DENSITY RANGE}

Globally, in both years, water in the SEPSAMW density range $\sigma_{\theta}=26.95-27.05 \mathrm{~kg} \mathrm{~m}^{-3}$ was formed through buoyancy gain from denser water. In 2005, freshening and cooling contributed 3.6 and $2.7 \mathrm{~Sv}$, respectively. In 2006, freshening formed 4.0 Sv, while $0.8 \mathrm{~Sv}$ were destroyed by heat gain. The net formation was $6.3 \mathrm{~Sv}$ in 2005 and 3.2 Sv in 2006 (Fig. 8 and Table A1).

In contrast to this global estimate, SEPSAMW within the Pacific Ocean sector, as well at its lowest PV source region (section $4 \mathrm{c}$ ), was predominantly formed from lighter water by buoyancy loss due to cooling. This is also true for the full SAMW density range within the Pacific (Fig. 9).

\section{3) Formation in the South AtLantic SAMW DENSITY RANGE}

Winter mixed layers are much shallower in the Atlantic sector of the Southern Ocean than in the Indian and Pacific sectors, resulting in weaker South Atlantic SAMW (Figs. 3a-e) (Tsuchiya et al. 1994; Provost et al. 1999). The global formation rates have a peak in 2006 (but not in 2005) at the density of South Atlantic mode water $\left(\sigma_{\theta}=26.5 \mathrm{~kg} \mathrm{~m}^{-3}\right)$ (Fig. 8). In 2006, this formation was from denser waters converted to SAMW through freshening and heat gain that were both more intense at higher densities.

Regionally, when the Walin integration is performed only over outcrops in the Atlantic sector, with corrections 
for isopycnal layer transports in and out of the sector, the result is similar: formation of South Atlantic SAMW from denser water through buoyancy gain (Fig. 9).

\section{b. Comparison with recent global Walin formation rate estimates}

The overall pattern of buoyancy gain (rather than buoyancy loss) due to freshening, and to a lesser extent heat gain, over the SAMW outcrop windows agrees with numerous previous studies (Marsh et al. 2000; Speer et al. 2000; Karstensen and Quadfasel 2002; Sallee et al. 2010). We compare our formation estimates with several recent estimates also obtained using the Walin method. Badin and Williams (2010), using two different air-sea flux climatologies, showed a transformation from dense to light water in the SAMW $\sigma_{\theta}$ range $26.8-27.2 \mathrm{~kg} \mathrm{~m}^{-3}$, whereas lighter waters $\left(25.0<\sigma_{\theta}<26.5 \mathrm{~kg} \mathrm{~m}^{-3}\right)$, outcropping farther equatorward, were transformed to denser waters by ocean heat loss. They estimated $16 \mathrm{~Sv}$ of formation of light water at $\sigma_{\theta}=26.6$ and $15 \mathrm{~Sv}$ of destruction of dense water at $\sigma_{\theta}=27.0$ emphasizing that the balance of freshwater and heat components differed in the three flux datasets.

Using a coarse resolution $\left(2^{\circ} \times 2^{\circ}\right)$ global coupled iceocean model, Iudicone et al. (2008a) found that south of $50^{\circ} \mathrm{S}$ the heat flux is uniformly close to zero or slightly positive (ocean heating) and the buoyancy flux is dominated by freshening. Their associated Walin analysis yielded formation of $40 \mathrm{~Sv}$ in the broad $\sigma_{\theta}$ range of 26.0$27.2 \mathrm{~kg} \mathrm{~m}^{-3}$, of which $12 \mathrm{~Sv}$ were formed by ocean heat loss from thermocline water (with $\sigma_{\theta}<26.0 \mathrm{~kg} \mathrm{~m}^{-3}$ ), while $28 \mathrm{~Sv}$ of the denser varieties of mode water were formed by freshening of denser waters. For comparison, averaged over 2005/06, SOSE formation of water in the $\sigma_{\theta}$ range $26.0-27.2 \mathrm{~kg} \mathrm{~m}^{-3}$ is $6.6 \mathrm{~Sv}$, with $11.0 \mathrm{~Sv}$ formed by freshwater flux (almost entirely by freshening of denser water) and $4.4 \mathrm{~Sv}$ destroyed by air-sea heat flux (almost entirely because of ocean heat loss, transforming more water out of than into the SAMW density range).

SOSE formation is thus weaker than Iudicone et al.'s (2008a) model-based result, and also weaker than Downes et al.'s (2011) results from the global $1^{\circ} \mathrm{ECCO}$ model and three free-running coupled climate models, which produced $26-51 \mathrm{~Sv}$ in the $\sigma_{\theta}$ range $26.0-27.2 \mathrm{~kg} \mathrm{~m}^{-3}$. The SOSE estimates of mode water formation are smaller because SOSE's adjusted surface fluxes show much weaker ocean heat loss over the whole Southern Ocean and lower precipitation in the polar regions compared to the other widely used air-sea flux products, such as NCEP1, ERA-Interim, and LY09 (Cerovečki et al. 2011), resulting in smaller differential cooling and freshwater gain over the outcrops bounding the wide SAMW density range considered in the other studies ( $\sigma_{\theta}=26.0$ and $27.2 \mathrm{~kg} \mathrm{~m}^{-3}$ ) (see also the appendix).

The SAMW formation rate diagnosed from SOSE is closer to that diagnosed by Marsh et al. (2000) from a global isopycnal general circulation model. They estimated $11 \mathrm{~Sv}$ of SAMW formation in the circumpolar zone $25^{\circ}-42.5^{\circ} \mathrm{S}$ primarily resulting from surface cooling, whereas south of $42.5^{\circ} \mathrm{S}$ water mass transformation in the SAMW density range was due to buoyancy gain (freshening dominating over cooling), which together with equally important diapycnal mixing formed a net 4.5 Sv of dense SAMW and AAIW.

Although the rates differ, the patterns of transformation in SOSE and in these other results are similar, with water in the SEPSAMW and SEISAMW density ranges formed mainly through buoyancy gain due to freshening and to a lesser extent heat gain, while lighter waters (with $\sigma_{\theta}<26.2 \mathrm{~kg} \mathrm{~m}^{-3}$ ) were formed through heat loss and evaporation.

\section{c. Seasonal and geographic distributions of SAMW formation}

The seasonal cycle of buoyancy gain and loss for each global density outcrop is depicted through monthly averages of the five-day-averaged transformation rate estimates from section 4a (Fig. 10). From April through September (austral winter), transformation rates are positive (the ocean loses buoyancy), while from October through March (austral summer), transformation rates are negative (the ocean gains buoyancy), as expected. Transformations resulting from winter cooling and summer warming, whose magnitude reaches more than $200 \mathrm{~Sv}$ at the lower densities shown in Fig. 10, nearly cancel, so that the annually averaged transformation rates, of less than $10 \mathrm{~Sv}$, are much smaller than the monthly mean rates.

Following Brambilla et al. (2008) and Maze et al. (2009), we next consider geographical maps of transformation and formation for different seasons and the annual mean, which provide more physical understanding of the water mass formation process. Figures 11 and 12 show that both the SEISAMW and SEPSAMW outcrop windows move poleward in summer (OctoberMarch) and equatorward in winter (April-September), as expected.

The strongest local transformation of water into the SEISAMW density range is due to large ocean buoyancy loss during austral winter south of Australia and New Zealand as well as in the central South Pacific (Figs. $11 \mathrm{c}, \mathrm{e}$ ). Here more water is added at $\sigma_{\theta}=$ $26.75 \mathrm{~kg} \mathrm{~m}^{-3}$ than is removed at $\sigma_{\theta}=26.85 \mathrm{~kg} \mathrm{~m}^{-3}$ (cf. Figs. 11c,d), resulting in SEISAMW formation (Figs. 13c,e). 

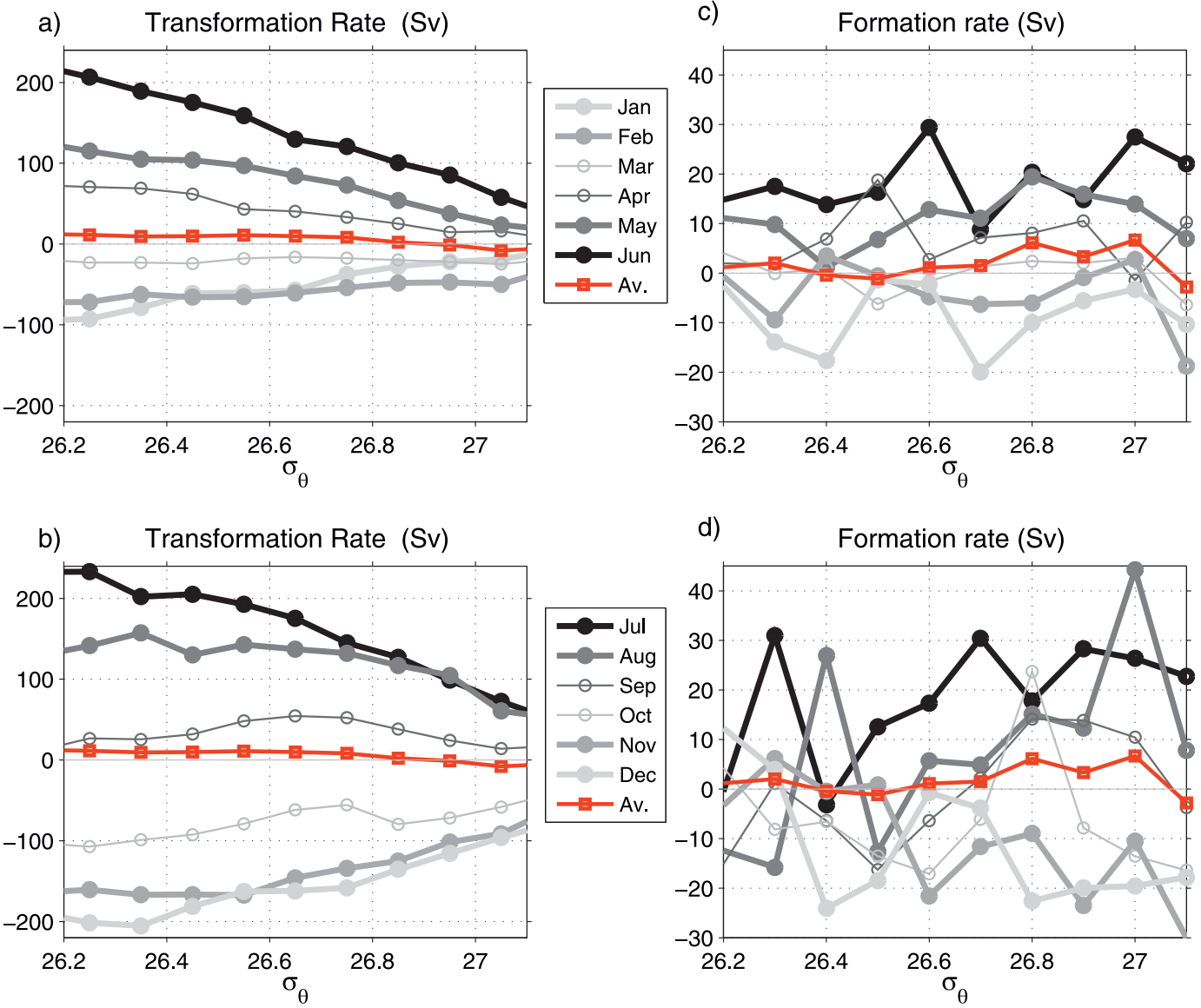

FIG. 10. Monthly mean estimates of (left) transformation and (right) formation (Sv), using SOSE five-day-averaged buoyancy flux (shown in Fig. 1) and sea surface density. Estimates are for the global ocean south of $24.7^{\circ} \mathrm{S}$, timeaveraged for 2005/06. Red lines show transformation and formation rates averaged over 2005/06, identical to the black lines in Figs. 8e,f.

These SEISAMW formation regions coincide with the location of deepest winter mixed layers (Dong et al. 2008) and the lowest PV pools in the SEISAMW density range (Figs. 4a-c).

The southeast Pacific is another region with strong winter transformation of water into the SEISAMW density range by ocean buoyancy loss, which, however, removes more water out of the SEISAMW density range (to become denser than $\sigma_{\theta}=26.85 \mathrm{~kg} \mathrm{~m}^{-3}$ ) than adds by the transformation of lighter water (with $\sigma_{\theta}<$ $26.75 \mathrm{~kg} \mathrm{~m}^{-3}$ ) into the SEISAMW density range, yielding net destruction of water in the SEISAMW density range in this region (Fig. 13c).

In the SEPSAMW formation region off the coast of Chile, air-sea buoyancy (heat) loss transforms more water into than out of the SEPSAMW density range (Figs. 12c,d), yielding SEPSAMW formation (Figs. 13d,f). The SEPSAMW formation region coincides with the location of deep winter mixed layers (Dong et al. 2008 contours shown on the maps).
The transformation and formation maps thus reveal information that the integrated global Walin calculations obscure. For both SEPSAMW and SEISAMW, differential buoyancy loss leads to formation of water in the region of the lowest PV SAMWs; the transformation maps show that at the SAMW formation sites in the southeast Indian and southeast Pacific Ocean marked by lowest PV, these water masses are formed only from lighter water by strong ocean buoyancy (heat) loss in austral winter. For SEPSAMW, conclusions from the maps match the Pacific-wide Walin calculation, with the most developed (lowest PV) SEPSAMW formed through buoyancy loss, even though the global Walin calculation yields formation of SEPSAMW density class water through buoyancy gain. For SEISAMW, in contrast, both the Indian-only and global Walin calculations show that SEISAMW density class water is formed by differential buoyancy gain, dominated by freshwater gain, whereas the lowest PV pool is associated with buoyancy loss resulting from cooling. 

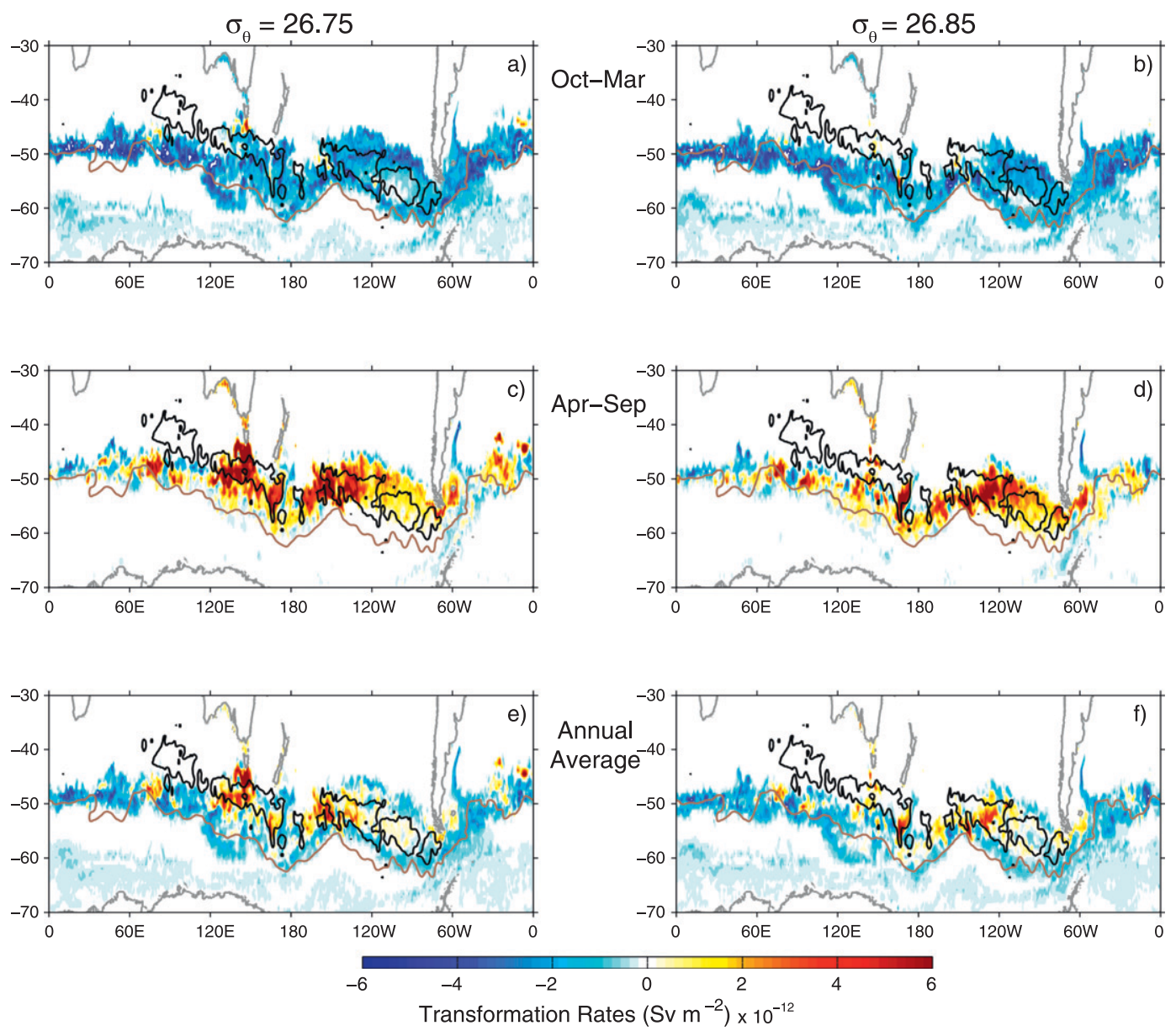

FIG. 11. Average transformation rates for SEISAMW [(left) $\sigma_{\theta}=26.75$ and (right) 26.85; $\left.\mathrm{Sv} \mathrm{m}^{-2}\right]$ for 2005/06 for (top) October-March, (middle) April-September, and (bottom) the annual average. Positive values indicate that the water is becoming denser. The black lines are the 300-m contour of September mixed layer depths from Dong et al. (2008), and the gray line is the climatological position of the PF (Orsi et al. 1995).

\section{SAMW volume budget}

The formation/destruction rate associated with diapycnal mixing within the Southern Ocean south of $30^{\circ} \mathrm{S}$ is the difference between the storage (volume change) (section 5b), and volume transport across $30^{\circ} \mathrm{S}$ (section $5 a$ ), and air-sea flux formation [Eq. (7)]. The shortcoming of this method is that it does not provide information about where mixing takes place geographically, how deep it occurs in the water column, or which physical processes are responsible for this mixing. We consider this budget not only for the Southern Ocean as a whole, but also in the Indian, Pacific, and Atlantic sectors individually.

\section{a. Volume transport across $30^{\circ} \mathrm{S}$ and between ocean sectors}

Volume transport across the complete $30^{\circ} \mathrm{S}$ section (Fig. 14a and Table 1) is divided into southward transport of upper thermocline water at densities lower than $\sigma_{\theta}=$ $25.5 \mathrm{~kg} \mathrm{~m}^{-3}$ and net northward transport of $31.0 \mathrm{~Sv}$ of the subducted, denser underlying layer at higher densities, where the maximum density considered here is $27.1 \mathrm{~kg} \mathrm{~m}^{-3}$ for reasons described in section $2 \mathrm{~b}$. This northward transport is distributed over all three ocean sectors. The globally integrated northward transport peaks at $\sigma_{\theta}=26.6-26.8 \mathrm{~kg} \mathrm{~m}^{-3}$, due to the northward transport of SEISAMW in the Indian Ocean, and remains high at the higher densities of SEPSAMW in the Pacific, and of AAIW in the Atlantic. In Talley (2003, 2008) (Table 1), the crossover between southward and northward transport was at a higher density $\left(\sigma_{\theta}\right.$ from 26.4 to $26.5 \mathrm{~kg} \mathrm{~m}^{-3}$ ) than in SOSE. SOSE's northward transport between $\sigma_{\theta}=25.5$ and $25.8 \mathrm{~kg} \mathrm{~m}^{-3}$ mostly lies in the Pacific, associated with the Subtropical Mode Water of the East Australian Current (Roemmich and Cornuelle 1992), and its northward transport between 

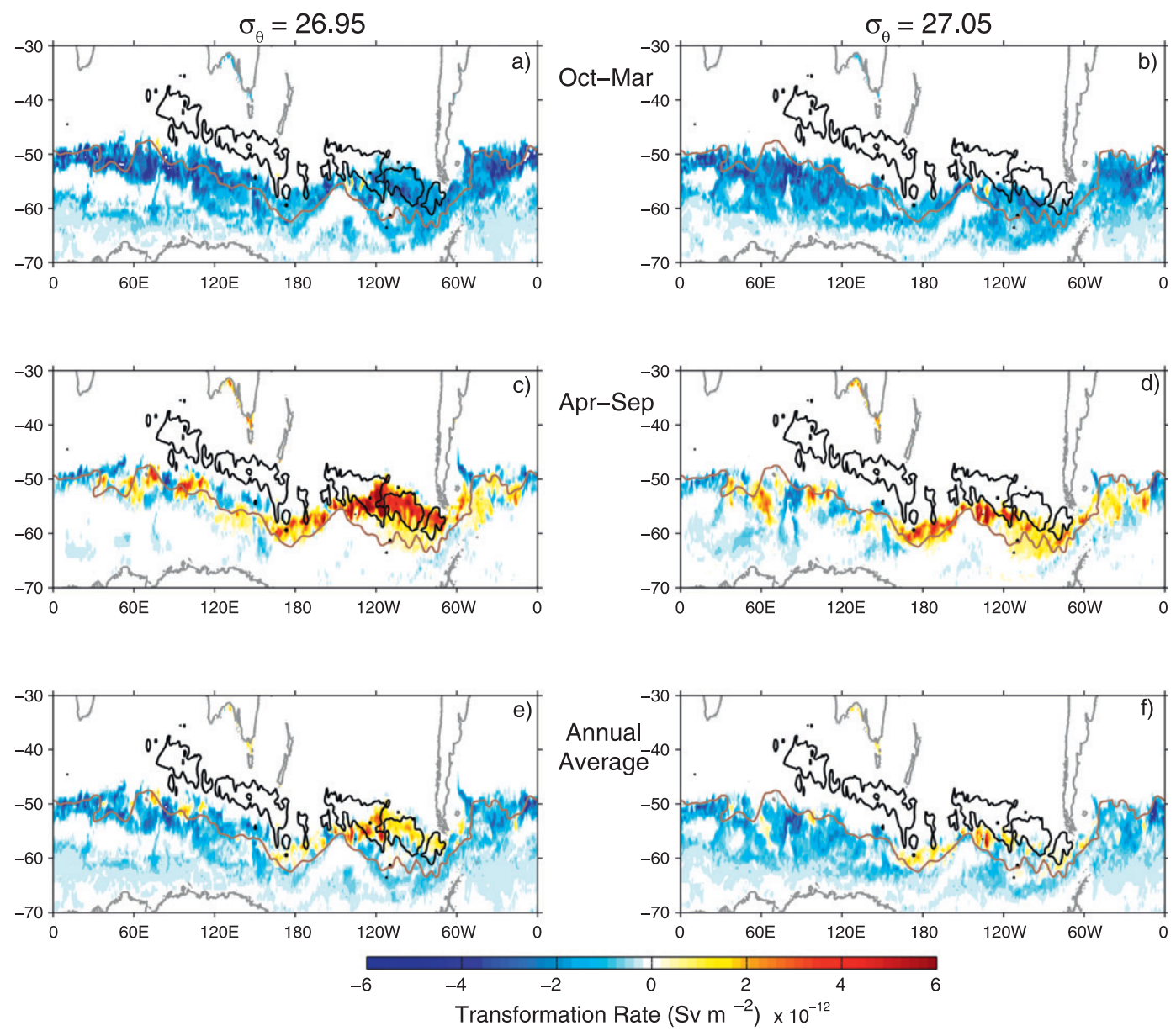

FIG. 12. As in Fig. 11, but for SEPSAMW: (left) $\sigma_{\theta}=26.95$ and (right) 27.05.

$\sigma_{\theta}=25.8$ and $26.6 \mathrm{~kg} \mathrm{~m}^{-3}$ mostly lies in the Atlantic associated with the Subtropical Mode Water of the Brazil Current (Provost et al. 1999).

Focusing on SAMW transports in the $\sigma_{\theta}$ range 26.7$27.0 \mathrm{~kg} \mathrm{~m}^{-3}$, SOSE's northward transport is similar to Talley's (2003) in all ocean sectors. SOSE's transport in the Pacific (4.6 Sv) and Atlantic (4.4 Sv) sectors agree well with Talley (2003) values 2.2 and $4.1 \mathrm{~Sv}$, respectively (Table 1). In the Indian Ocean, both Talley (2003) and SOSE yield northward transport of $1.5 \mathrm{~Sv}$ in the lighter SEISAMW $\sigma_{\theta}$ range $26.7-26.89 \mathrm{~kg} \mathrm{~m}^{-3}$, and southward transport in the denser $\sigma_{\theta}$ range 26.89$27.0 \mathrm{~kg} \mathrm{~m}^{-3}$, lying between SEISAMW and AAIW $(-1.5$ and $-1.1 \mathrm{~Sv}$, respectively).

Also, estimates of Iudicone et al. (2008a,c) of northward transport across $30^{\circ} \mathrm{S}$ in the $\sigma_{\theta}$ range 26.0$27.2 \mathrm{~kg} \mathrm{~m}^{-3}$ (7.2, 2.7, and 9.5 Sv in the Pacific, Indian, and Atlantic) are similar to the corresponding SOSE estimates of 7.9, 3.1, and $14.5 \mathrm{~Sv}$, respectively (Table 1).

Between the ocean sectors, the eastward flow of SAMW $\left(\sigma_{\theta}=26.7-27.1 \mathrm{~kg} \mathrm{~m}^{-3}\right)$ is the strongest from the Indian to the Pacific (43 Sv) (Figs. 14 e-g; Table 2). It decreases to $36 \mathrm{~Sv}$ from the Pacific to the Atlantic Ocean and further to $26 \mathrm{~Sv}$ from the Atlantic to the Indian. This pattern reflects the dominance of SAMW formation in the southeast Indian Ocean.

\section{b. Storage rate in isopycnal layers}

A nonzero storage rate (volume change) [Eq. (7)] is a consequence of the nonstationarity of this 2-yr estimate. The rates of volume change each year were comparable to the formation, advective export, and destruction rates (Figs. 14h-k compared with the advective transports in Figs. 14a-g). Volume loss occurred at the SAMW and AAIW densities ( $\sigma_{\theta}$ range 26.4$27.0 \mathrm{~kg} \mathrm{~m}^{-3}$ ), with compensating volume gain predominantly at higher densities (Fig. 14h). Volume decrease was large in the Indian and Pacific, with a small volume increase in the Atlantic (Table 2). Maps of volume loss (not shown) show that the loss tends to be localized in the regions of lowest PV SAMW. Details of storage rates are provided in the next section 

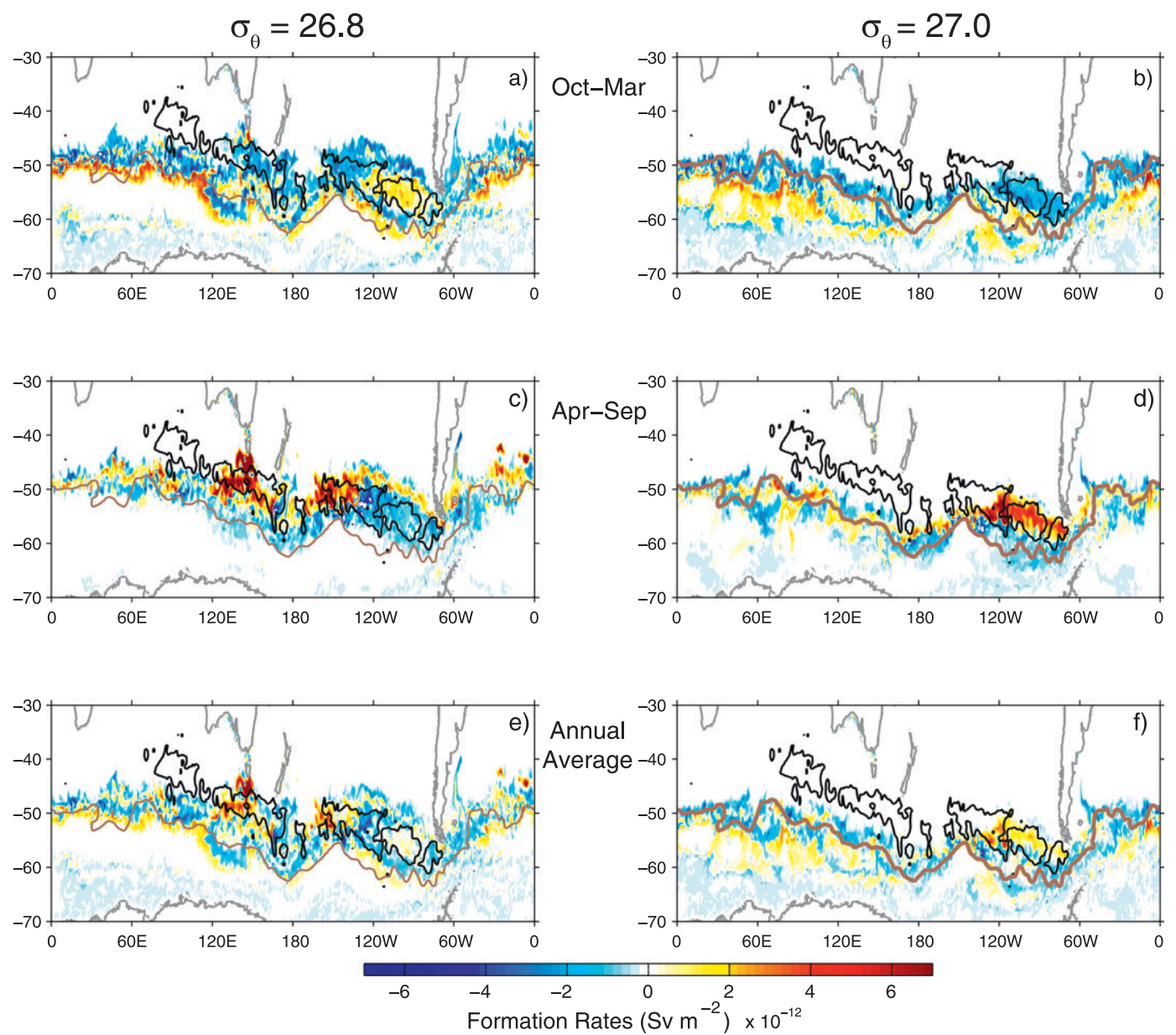

FIG. 13. Average formation rates for (left) SEISAMW $\left(\sigma_{\theta}=26.8\right)$ and (right) SEPSAMW $\left(\sigma_{\theta}=27.05\right) \mathrm{in} \mathrm{Sv} \mathrm{m}^{-2}$, for (top) October-March, (middle) April-September, and (bottom) the annual average. These maps are obtained by subtracting the transformation rate maps shown in Figs. $11\left(\sigma_{\theta}=26.85\right.$ minus $\left.\sigma_{\theta}=26.75\right)$ and $12\left(\sigma_{\theta}=27.05\right.$ minus $\left.\sigma_{\theta}=26.95\right)$, respectively. The black and gray lines are as in Fig. 11.

as they are required for calculation of the diapycnal mixing rate.

\section{c. SAMW formation/destruction budgets south of $30^{\circ} \mathrm{S}$}

We show here that water mass formation/destruction owing to diapycnal diffusive fluxes [ $D$ term in Eq. (2)] are comparable in magnitude to the air-sea flux formation rate, export transports, and storage rates; all contribute to the SAMW budget. Elevated diapycnal mixing is expected within and in the proximity of the surface mixed layer, where effective diffusivities are enhanced as shown from model results (Marshall et al. 1999; Iudicone et al. 2008b) and observations (e.g., Waterman et al. 2013). Similarly, Naveira Garabato et al. (2003) shows that the diapycnal transformation of SAMW in the Scotia Sea is primarily driven by upper-ocean mixing processes (while the topographically induced mixing transforms denser water masses found 1500-2000 $\mathrm{m}$ above the ocean floor). Observations also show enhanced diffusivities in the regions close to the strong ACC fronts (Sloyan et al. 2010; St. Laurent et al. 2012).

We first consider the broad $\sigma_{\theta}$ range $26.5-27.1 \mathrm{~kg} \mathrm{~m}^{-3}$, which includes all varieties of SAMW discussed in section 4 , both in terms of the global (circumpolar) outcrops and in each ocean sector separately (Tables 2 and 3; Fig. 15). We then highlight narrow density ranges of the SEISAMW, SEPSAMW, and the weaker South Atlantic SAMW (Table 3).

\section{1) SOUTHERn OCEAn as A WHOle}

Considering the global SAMW budget south of $30^{\circ} \mathrm{S}$, net formation in the density range $26.5-27.1 \mathrm{~kg} \mathrm{~m}^{-3}$ was $(13.2,6.8)$ Sv for $(2005,2006)$ (Table 2a). The northward transport across $30^{\circ} \mathrm{S}$ was $(18.2,17.1) \mathrm{Sv}$ and the volume 
a) Southern Ocean $30^{\circ} \mathrm{S}$

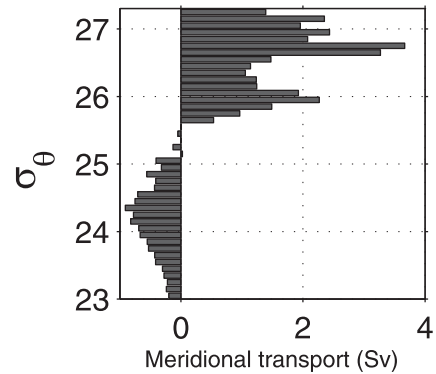

e) Indian to Pacific

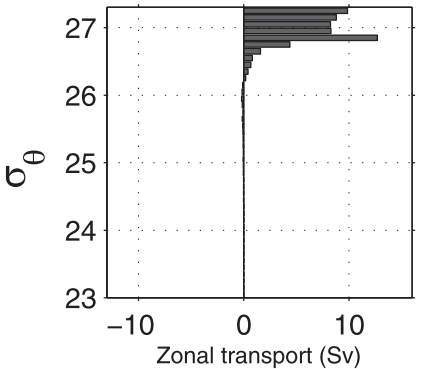

h) Southern Ocean

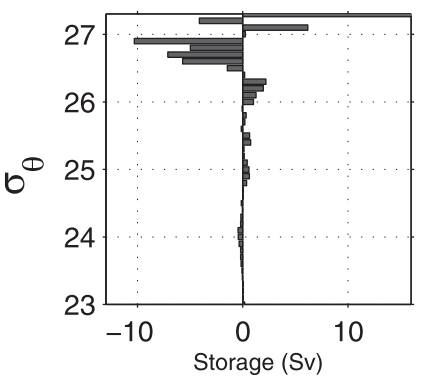

b) S. Pacific $30^{\circ} \mathrm{S}$

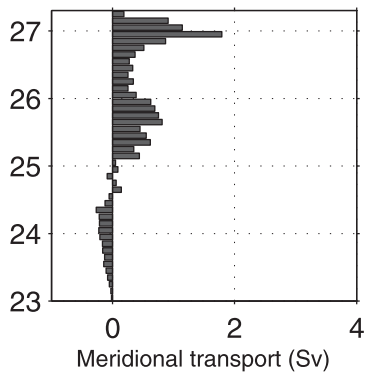

f) Pacific to Atlantic

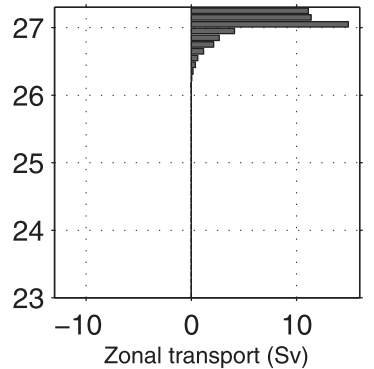

i) S. Pacific

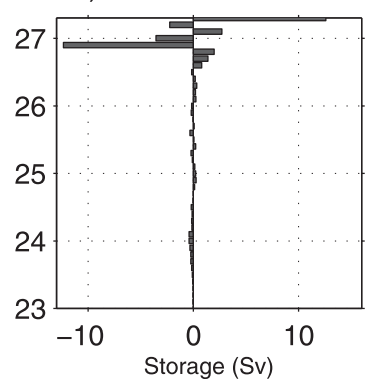

c) Indian $30^{\circ} \mathrm{S}$

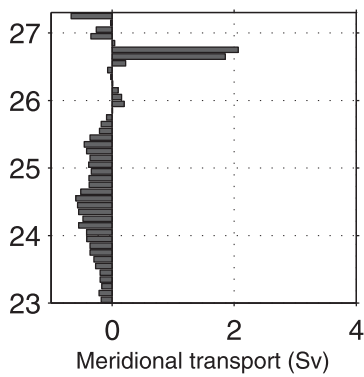

g) Atlantic to Indian
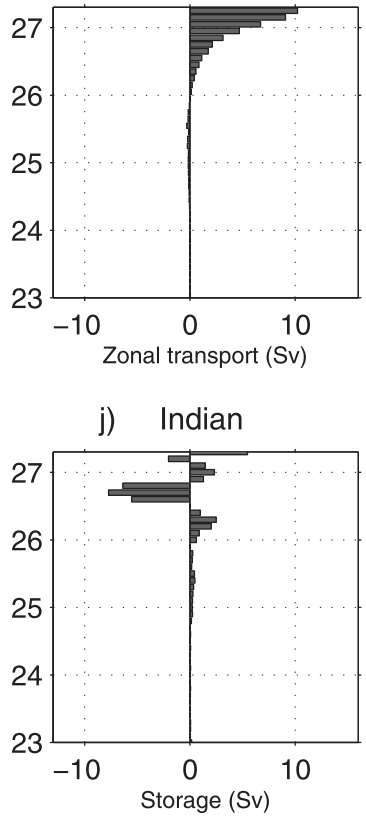

d) S. Atlantic $30^{\circ} \mathrm{S}$

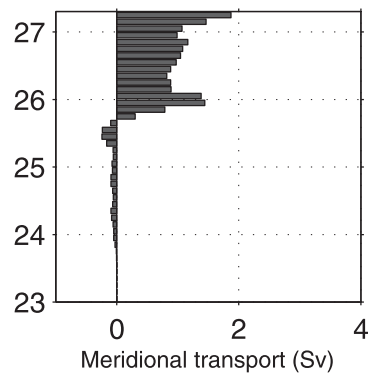

FIG. 14. (a)-(d) Meridional volume transport (Sv) across $30^{\circ} \mathrm{S}$, (e)-(g) zonal transport between the individual ocean sectors, and (h)-(k) storage rate for period 2005/06. Note different scales in (a)-(d) and (e)-(k). Positive transport is northward in (a)-(d) and eastward in (e) $-(\mathrm{g})$. The longitude bounds are: $150^{\circ} \mathrm{E}-70^{\circ} \mathrm{W}$ for the Pacific sector, $70^{\circ} \mathrm{W}-20^{\circ} \mathrm{E}$ for the Atlantic sector, and $20^{\circ}-150^{\circ} \mathrm{E}$ for the Indian sector.

decreased at a rate of $(-19.3,-22.9)$ Sv. Therefore approximately $(14.5,12.6) \mathrm{Sv}$ of SAMW was removed by diapycnal mixing (Fig. 15a).

In the narrower density range $\left(\sigma_{\theta}=26.7-27.1 \mathrm{~kg} \mathrm{~m}^{-3}\right)$ the balance is similar. Air-sea buoyancy fluxes formed $(13.5,1.9) \mathrm{Sv}$ (Table 2b). Combined with the northward transport of $(13.4,12.6) \mathrm{Sv}$ across $30^{\circ} \mathrm{S}$, and a storage rate of $(-7.8,-23.3) \mathrm{Sv}$, diapycnal mixing removed SAMW at a rate of $(7.9,12.6) \mathrm{Sv}$ predominantly in the Pacific Ocean.

Thus, air-sea fluxes and diapycnal mixing play equally important roles in the SAMW budget. We might conclude that the overall SAMW budget of formation and destruction is nearly closed south of $30^{\circ} \mathrm{S}$. However, since the northward transport of SAMW out of the Southern Ocean and the rate of volume loss are similarly large, it is difficult to speculate about which terms would balance in a long-term climatological mean for which the storage rate should be negligible.

\section{2) INDIAN OCEAN}

In the Indian Ocean, SAMW in the broad $\sigma_{\theta}$ range $26.5-27.1 \mathrm{~kg} \mathrm{~m}^{-3}$ is formed predominantly by buoyancy gain from denser water $(9.4,10.9) \mathrm{Sv}$. Advection imports $(29.8,27.9) \mathrm{Sv}$ from the Atlantic, exports (45.3, 45.1) Sv eastward to the Pacific (Table 2a; Figs. 14e,g), and exports a much smaller $(3.6,2.9)$ Sv northward across $30^{\circ} \mathrm{S}$. Thus overall, transports out of the Indian Ocean exceed import by $(19.1,20.1) \mathrm{Sv}$, which can be associated with the large SEISAMW formation compared with SEPSAMW and South Atlantic SAMW formation. Taken together with formation of $(9.4,10.9)$ Sv by air-sea 
TABLE 1. Time averaged (2005/06) meridional volume transport estimates (Sv) across $30^{\circ} \mathrm{S}$ from SOSE compared with Talley (2003) and Iudicone et al. (2008a).

\begin{tabular}{lcccc}
\hline \hline $\begin{array}{c}\text { Ocean } \\
\text { sector }\end{array}$ & Density range & $\begin{array}{c}\text { Talley } \\
(2003) \\
\text { transports }\end{array}$ & $\begin{array}{c}\text { SOSE } \\
\text { transports }\end{array}$ & $\begin{array}{c}\text { Iudicone et al. } \\
(2008 \mathrm{a}, \mathrm{c}) \\
\text { transports }\end{array}$ \\
\hline Pacific & $26.7<\sigma_{\theta}<27.0$ & 2.2 & 4.6 & \\
Atlantic & $26.7<\sigma_{\theta}<27.0$ & 4.1 & 4.4 & \\
Indian & $26.7<\sigma_{\theta}<26.89$ & 1.5 & 1.5 & \\
Indian & $26.89<\sigma_{\theta}<27.0$ & -1.5 & -1.1 & \\
Pacific & $26.0<\sigma_{\theta}<27.2$ & & 7.9 & 7.2 \\
Atlantic & $26.0<\sigma_{\theta}<27.2$ & & 14.5 & 9.5 \\
Indian & $26.0<\sigma_{\theta}<27.2$ & & 3.1 & 2.7 \\
\hline
\end{tabular}

fluxes, and a storage rate (volume loss) of $(-16.3,-12.3)$ $\mathrm{Sv}$, we estimate that diapycnal mixing removes $(-6.6$, -3.1) Sv (Table 2a, Fig. 15b). Thus a large amount of Indian SAMW is formed through air-sea fluxes, and almost half of this volume is destroyed in Indian Ocean through diapycnal mixing.

In the narrower $\sigma_{\theta}$ range $\left(26.7-27.1 \mathrm{~kg} \mathrm{~m}^{-3}\right)$, there is net formation by air-sea buoyancy fluxes $(8.5,6.3) \mathrm{Sv}$, net export of $(17.1,18.8) \mathrm{Sv}$ mostly eastward to the Pacific, and volume loss of $(-7.3,-11.5) \mathrm{Sv}$, from which we diagnose weak formation by diapycnal mixing (1.3, 1.0) Sv (Table 2b).

In the narrowest density range $26.75-26.85 \sigma_{\theta}$, associated with the lowest PV SEISAMW, there is a net formation by air-sea buoyancy fluxes $(7.1,7.8) \mathrm{Sv}$, and destruction by diapycnal mixing $(-5.5,-1.0 \mathrm{~Sv}$; Table 3$)$. Zonal export to the Pacific $(13.0,12.7) \mathrm{Sv}$ in this SEISAW range remains much stronger than import from the Atlantic $(3.7,2.7) \mathrm{Sv}$.

Largely consistent with the results presented here, Sloyan and Rintoul (2001b) used a static inverse box model to infer that the largest SAMW formation is in the Indian sector of the Southern Ocean, where formation in the $\sigma_{\theta}$ range $26.0-27.0 \mathrm{~kg} \mathrm{~m}^{-3}$ is from both lighter and denser water: $4.4 \pm 2.0 \mathrm{~Sv}$ of thermocline water transforms into SAMW, joined by $11.7 \pm 1.0 \mathrm{~Sv}$ of Antarctic Surface Water, which is advected northward in the Ekman layer, warmed, freshened, and transformed to
SAMW densities, for a net formation of 16.1 Sv by airsea fluxes. They estimate $4 \pm 2 \mathrm{~Sv}$ of SAMW destruction by diapycnal mixing as it is converted to denser water. (In SOSE, averaged over two years in the $\sigma_{\theta}$ range 26.0$27.0 \mathrm{~kg} \mathrm{~m}^{-3}, 6.8 \mathrm{~Sv}$ are formed by air-sea fluxes, $3.5 \mathrm{~Sv}$ are exported northward, $37.5 \mathrm{~Sv}$ are transported into the Pacific, and 21.9 Sv are transported from the Atlantic. Since the storage rate was $-8.9 \mathrm{~Sv}$, diapycnal mixing is inferred to have formed $3.4 \mathrm{~Sv}$.)

Similar to our results are also results of Marsh et al. (2000), who analyzed a coarse-resolution (mesh $1.25^{\circ}$ ) global isopycnal general circulation model, with parameterized eddy effects, and found that SAMW forms predominantly in the Indian Ocean, at a rate of $20 \mathrm{~Sv}$. Similar to our results they also show that (south of $42.5^{\circ}$ ) the effects of surface fluxes and mixing are roughly equally important in water mass transformation in the SAMW density range.

\section{3) PACIFIC OCEAN}

In the Pacific in the $\sigma_{\theta}=26.5-27.1 \mathrm{~kg} \mathrm{~m}^{-3}$ range, airsea fluxes destroyed $(-1.1,-4.6) \mathrm{Sv}$. This was not large enough to balance the small net advective inflow of (1.7, 1.0) $\mathrm{Sv}$, and the volume decrease at $(-5.0,-12.0) \mathrm{Sv}$. Therefore diapycnal mixing rate is estimated to have removed $(-5.6,-8.4) \mathrm{Sv}$ in this density range (Table 2a, Fig. 15c).

In the somewhat narrower density range $\left(\sigma_{\theta}=26.7-\right.$ $\left.27.1 \mathrm{~kg} \mathrm{~m}^{-3}\right)$, the budget is qualitatively similar: (42.8, 42.8) Sv was transported into the Pacific from the Indian, $(35.5,35.9) \mathrm{Sv}$ was transported out to the Atlantic, and $(6.0,5.5) \mathrm{Sv}$ was transported northward, yielding a near balance of $(1.3,1.4)$ Sv inflow in the Pacific. SAMW in this range can be either formed or destroyed by air-sea buoyancy fluxes: $(2.2,-1.0) \mathrm{Sv}$. The volume loss rate was $(-5.4,-13.2) \mathrm{Sv}$, implying that $(-8.9,-13.6) \mathrm{Sv}$ was destroyed by diapycnal mixing (Table $2 b$ ).

Looking at the narrowest density range $\left(26.95<\sigma_{\theta}<\right.$ $27.05 \mathrm{~kg} \mathrm{~m}^{-3}$ ), which is characteristic of SEPSAMW (Table 3), air-sea buoyancy fluxes formed $(5.6,4.1) \mathrm{Sv}$. This is unlike the net destruction or weak formation obtained for the wider density ranges that included the

TABLE 2a. SAMW volume budget (Sv) for $\sigma_{\theta}$ range $26.5-27.1 \mathrm{~kg} \mathrm{~m}^{-3}$ in each ocean sector for years 2005 (first entry) and 2006 (second entry).

\begin{tabular}{lcccccc}
\hline \hline & $\begin{array}{c}\text { Meridional } \\
\text { transport across } \\
\text { Ocean sector }\end{array}$ & $\begin{array}{c}\text { Zonal transport } \\
\text { into ocean } \\
\text { sector }(\mathrm{b})\end{array}$ & $\begin{array}{c}\text { Zonal transport } \\
\text { out of an ocean } \\
\text { sector }(\mathrm{c})\end{array}$ & $\begin{array}{c}\text { Formation by } \\
\text { air-sea buoyancy } \\
\text { fluxes }(\mathrm{d})\end{array}$ & $\begin{array}{c}\text { Formation by } \\
\text { Storage rate }(\mathrm{e})\end{array}$ & $\begin{array}{c}\text { diapycnal mixing } \\
(\mathrm{a}-\mathrm{b}+\mathrm{c}-\mathrm{d}+\mathrm{e})\end{array}$ \\
\hline Indian & $3.6,2.9$ & $29.8,27.9$ & $45.3,45.1$ & $9.4,10.9$ & $-16.3,-12.3$ & $-6.6,-3.1$ \\
South Pacific & $6.6,6.1$ & $45.3,45.1$ & $37.0,38.0$ & $-1.1,-4.6$ & $-5.0,-12.0$ & $-5.6,-8.4$ \\
South Atlantic & $7.9,8.1$ & $37.0,38.0$ & $29.8,27.9$ & $5.0,0.5$ & $2.0,1.4$ & $-2.3,-1.1$ \\
Southern Ocean & $18.2,17.1$ & & & $13.2,6.8$ & $-19.3,-22.9$ & $-14.5,-12.6$ \\
\hline
\end{tabular}


TABLE 2b. SAMW volume budget for $\sigma_{\theta}$ range 26.7-27.1 $\mathrm{kg} \mathrm{m}^{-3}$ in each ocean sector for years 2005 (first entry) and 2006 (second entry).

\begin{tabular}{lcccccc}
\hline \hline & $\begin{array}{c}\text { Meridional } \\
\text { transport across } \\
\text { Ocean sector }\end{array}$ & $\begin{array}{c}\text { Zonal transport } \\
\text { into ocean } \\
\text { sector }(\mathrm{b})\end{array}$ & $\begin{array}{c}\text { Zonal transport } \\
\text { out of an ocean } \\
\text { sector }(\mathrm{c})\end{array}$ & $\begin{array}{c}\text { Formation by } \\
\text { air-sea buoyancy } \\
\text { fluxes }(\mathrm{d})\end{array}$ & $\begin{array}{c}\text { Formation by } \\
\text { Storage rate }(\mathrm{e})\end{array}$ & $\begin{array}{c}\text { diapycnal mixing } \\
(\mathrm{a}-\mathrm{b}+\mathrm{c}-\mathrm{d}+\mathrm{e})\end{array}$ \\
\hline Indian & $1.5,1.0$ & $27.2,25.0$ & $42.8,42.8$ & $8.5,6.3$ & $-7.3,-11.5$ & $1.3,1.0$ \\
South Pacific & $6.0,5.5$ & $42.8,42.8$ & $35.5,35.9$ & $2.2,-1.0$ & $-5.4,-13.2$ & $-8.9,-13.6$ \\
South Atlantic & $5.9,6.1$ & $35.5,35.9$ & $27.2,25.0$ & $2.8,-3.4$ & $4.8,1.4$ & $-0.4,0.0$ \\
Southern Ocean & $13.4,12.6$ & & & $13.5,1.9$ & $-7.8,-23.3$ & $-7.9,-12.6$ \\
\hline
\end{tabular}

inflowing SEISAMW, which is partially destoyed in the Pacific through air-sea fluxes (likely through conversion to SEPSAMW). Net advective export was $(-8.7,-7.7) \mathrm{Sv}$, and the volume decrease was $(-2.6,-4.8) \mathrm{Sv}$. The diagnosed diapycnal nearly zero formation or destruction is therefore $(0.5,-1.2) \mathrm{Sv}$.
As in SOSE, Sloyan and Rintoul (2001b) inferred strong destruction in the broad $\sigma_{\theta}$ range $26.0-27.0 \mathrm{~kg} \mathrm{~m}^{-3}$ by diapycnal mixing in the Pacific: $8 \mathrm{~Sv}$ of cold and fresh SAMW was transformed to thermocline water by a combined effect of air-sea buoyancy fluxes and diapycnal fluxes, and $10.4 \pm 2.0 \mathrm{~Sv}$ of SAMW was transformed

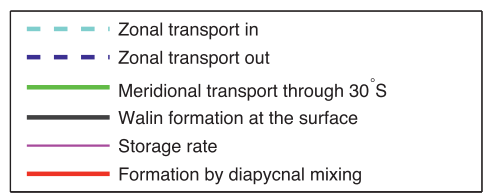

a) Southern Ocean

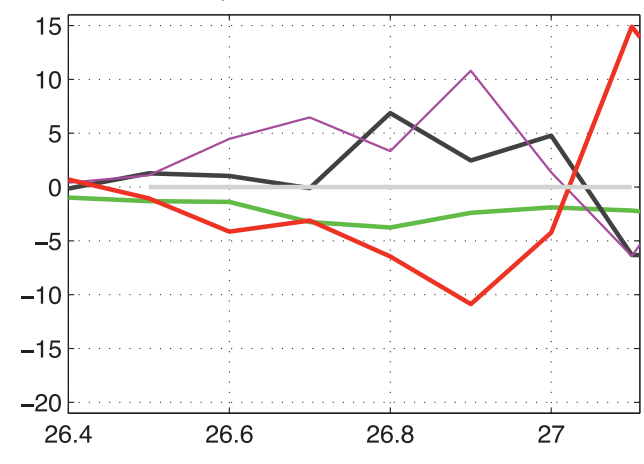

c) S. Pacific

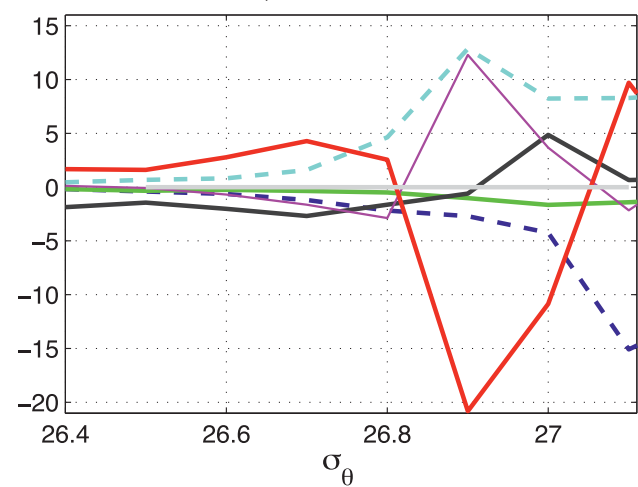

b) Indian Ocean

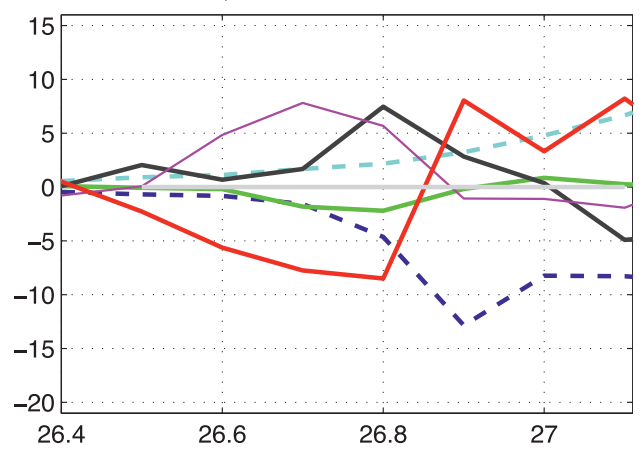

d) S. Atlantic

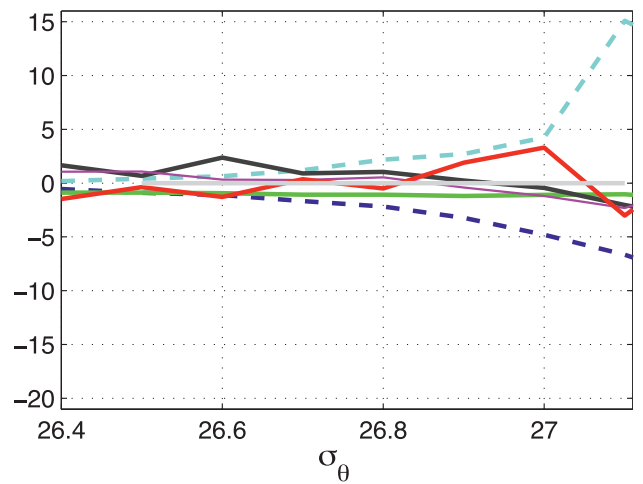

FIG. 15. Average (2005/06) net transports south of $30^{\circ} \mathrm{S}$ in isopycnal layers $0.1 \mathrm{~kg} \mathrm{~m}^{-3}$ wide for (a) Southern Ocean (sum of all sectors), (b) Indian Ocean, (c) South Pacific, and (d) South Atlantic, showing zonal transport (Sv) in and out of each ocean sector, meridional transport $(\mathrm{Sv})$ across $30^{\circ} \mathrm{S}$, formation by air-sea buoyancy fluxes estimated from Walin analysis, and the residual transport, which is ascribed to the effects of diapycnal mixing on volume balance in that isopycnal layer; colors are indicated in the legend. Positive transports are transports into the ocean basin and negative transports are out of the ocean basin. The storage term is $-d V / d t$ where $V$ is total volume, plotted with a negative sign to emphasize the full balance of terms. The budget is estimated from Eq. (7). 
TABLE 3. As in Table 2, but for narrow density ranges characteristic of the more prounounced SAMWs, and within individual ocean sectors. Volume budget $(\mathrm{Sv})$ for SEISAMW $\left(\sigma_{\theta}\right.$ range $\left.26.75-26.85 \mathrm{~kg} \mathrm{~m}^{-3}\right)$, SEPSAMW $\left(\sigma_{\theta}\right.$ range $\left.26.95-27.05 \mathrm{~kg} \mathrm{~m}^{-3}\right)$ and South Atlantic SAMW (Atlantic sector) $\left(\sigma_{\theta}\right.$ range $26.55-26.65 \mathrm{~kg} \mathrm{~m}^{-3}$ ) for years 2005, 2006.

\begin{tabular}{lcccccr}
\hline \hline Water mass & $\begin{array}{c}\text { Meridional } \\
\text { transport across } \\
30^{\circ} \mathrm{S}(\mathrm{a})\end{array}$ & $\begin{array}{c}\text { Zonal transport } \\
\text { into ocean } \\
\text { sector }(\mathrm{b})\end{array}$ & $\begin{array}{c}\text { Zonal transport } \\
\text { out of an ocean } \\
\text { sector }(\mathrm{c})\end{array}$ & $\begin{array}{c}\text { Formation by } \\
\text { air-sea buoyancy } \\
\text { fluxes }(\mathrm{d})\end{array}$ & $\begin{array}{c}\text { Formation by } \\
\text { Storage rate }(\mathrm{e})\end{array}$ & $\begin{array}{c}\text { diapycnal mixing } \\
(\mathrm{a}-\mathrm{b}+\mathrm{c}-\mathrm{d}+\mathrm{e})\end{array}$ \\
\hline SEISAMW & $0.3,0.1$ & $3.7,2.7$ & $13.0,12.7$ & $7.1,7.8$ & $-8.0,-3.3$ & $-5.5,-1.0$ \\
SEPSAMW & $1.6,1.2$ & $8.2,8.4$ & $15.3,14.9$ & $5.6,4.1$ & $-2.6,-4.8$ & $0.5,-1.2$ \\
S. Atlantic SAMW & $1.0,0.9$ & $1.0,1.4$ & $1.7,1.7$ & $1.8,2.9$ & $-1.0,0.3$ & $-1.1,-1.4$ \\
\hline
\end{tabular}

into denser water (AAIW and Upper Circumpolar Deep Water) by diapycnal mixing. Some of the $3.3 \pm$ $1 \mathrm{~Sv}$ of SAMW formed from Antarctic Surface Water is further converted to slightly denser AAIW. (For comparison, in SOSE, averaged over two years in the $\sigma_{\theta}$ range $26.0-27.0 \mathrm{~kg} \mathrm{~m}^{-3}, 1.6 \mathrm{~Sv}$ were destroyed by airsea fluxes, 6.7 Sv were exported northward, $37.5 \mathrm{~Sv}$ were transported into the Pacific, and $26.7 \mathrm{~Sv}$ were transported out of the Pacific into the Atlantic. The storage rate was $-10.3 \mathrm{~Sv}$, and therefore diapycnal mixing destroyed $12.8 \mathrm{~Sv}$.)

Also similar to our results, analyzing model output, Hasson et al. (2012) show that in the modeled Pacific just as in Indian sector, there is strong water mass transformation after these waters leave the winter mixed layer. Whereas in the Indian Ocean water mass transformation is predominantly due to isopycnal mixing (KochLarrouy et al. 2010), in the Pacific Ocean transformation occurs both because of isopycnal and diapycnal mixing.

\section{4) Atlantic Ocean}

The South Atlantic SAMW is much weaker than the Indian and Pacific SAMWs in terms of its PV signal (Fig. 3), and it has only a weak formation peak in the global surface formation rates (Fig. 8). In the broad SAMW density range $\left(\sigma_{\theta}=26.5-27.1 \mathrm{~kg} \mathrm{~m}^{-3}\right)$ there is import from the Pacific $(37.0,38.0) \mathrm{Sv}$, and export both northward across $30^{\circ} \mathrm{S}(7.9,8.1) \mathrm{Sv}$ and eastward into the Indian Ocean $(29.8,27.9) \mathrm{Sv}$, hence a small net loss or a net gain of $(-0.7,2.0)$ Sv by advective transports within the Atlantic (Table 2a, Fig. 15d). Air-sea fluxes form SAMW in the South Atlantic from denser waters at a rate of $(5.0,0.5) \mathrm{Sv}$ and since the volume of SAMW in the South Atlantic has increased by $(2.0,1.4)$ $\mathrm{Sv}$, a net destruction of $(-2.3,-1.1) \mathrm{Sv}$ of SAMW is ascribed to diapycnal mixing.

In the narrower density range $\left(\sigma_{\theta}=26.7-27.1 \mathrm{~kg} \mathrm{~m}^{-3}\right)$, air-sea fluxes yielded either formation or destruction $(2.8,-3.4)$ Sv. There was net advection into the Atlantic Ocean $(2.4,4.8)$ Sv because of the large Drake Passage transport of SEPSAMW, despite the robust northward transport out of the region. There was a net addition to the volume in the SAMW layer (4.8, 1.4) Sv. The balance for diapycnal mixing is close to zero $(-0.4,0.0) \mathrm{Sv}$.

For the narrowest density range characteristic of South Atlantic SAMW $\left(26.55<\sigma_{\theta}<26.65 \mathrm{~kg} \mathrm{~m}^{-3}\right)$ (Table 3), $(1.8,2.9) \mathrm{Sv}$ was formed by air-sea buoyancy fluxes. For this narrowest density range of Atlantic SAMW, there is a net export of $(-1.7,-1.2)$ Sv unlike the net inflow for the wider density range which includes the large import of SEPSAMW from the Pacific. Including the similar magnitude volume change of $(-1.0,0.3) \mathrm{Sv}$, we diagnose $(-1.1,-1.4) \mathrm{Sv}$ destroyed by diapycnal mixing.

Sloyan and Rintoul (2001b), for $\sigma_{\theta}=26.0-27.0 \mathrm{~kg} \mathrm{~m}^{-3}$, showed a cancelation between surface and interior SAMW transformation in the Atlantic Ocean, with air-sea buoyancy fluxes transforming $6.0 \pm 1.0 \mathrm{~Sv}$ of thermocline water into SAMW, which is more than compensated by diapycnal mixing converting $8.0 \pm 3.0 \mathrm{~Sv}$ of SAMW back into thermocline water.

\section{Discussion and conclusions}

The Southern Ocean (south of $30^{\circ} \mathrm{S}$ ) is characterized by globally important water mass transformations, including those that govern the upper ocean's SAMWs (e.g., Speer et al. 2000; Sloyan and Rintoul 2001a,b; Talley et al. 2003; Talley 2008). Formation and destruction rates by air-sea fluxes and by diapycnal mixing, as well as transports and storage, of waters in the SAMW density range were estimated here using the Southern Ocean State Estimate (SOSE) (Mazloff et al. 2010), which has eddy-permitting resolution and which is constrained to a large set of oceanic observations. Importantly for water mass formation analysis, SOSE provides both three-dimensional oceanic fields and adjusted air-sea fluxes that are dynamically consistent so that they exactly satisfy the ocean circulation model equations, which is central to water mass formation analysis. SAMW surface formation rates were calculated using Walin (1982) analysis with SOSE air-sea fluxes and surface densities for 2005 and 2006. Meridional transport of SAMW out of the Southern Ocean 
across $30^{\circ} \mathrm{S}$, zonal transport between the ocean basins, and the rate of volume change for each year were calculated. The SAMW formation/destruction rate resulting from diapycnal mixing was estimated as the residual of these other rates [Eq. (7)]. An important result is that all rates (air-sea fluxes, net advection, storage, diapycnal mixing) are of similar magnitude, so none can be neglected or considered to balance a single other rate.

Considering the entire Southern Ocean south of $30^{\circ} \mathrm{S}$ in the density range $26.5<\sigma_{\theta}<27.1 \mathrm{~kg} \mathrm{~m}^{-3}$, which includes SAMW, there was formation by air-sea fluxes $(13.2,6.8) \mathrm{Sv}$ for $(2005,2006)$ and destruction by diapycnal mixing $(-14.5,-12.6) \mathrm{Sv}$. (Qualitatively similar results were obtained for a slightly narrower density range.) There was a net northward export out of the Southern Ocean of $(18.2,17.1)$ Sv (distributed over all three ocean basins) and a significant loss of volume at a rate of $(-19.3,-22.9)$ Sv over the two years of the SOSE output. One interpretation could be that the Southern Ocean south of $30^{\circ} \mathrm{S}$ is a sufficiently large region that the water in the SAMW density range is nearly self-contained, with most of the water formed through air-sea fluxes subsequently destroyed through diapycnal mixing, as concluded by Marshall et al. (1999) for a large region of the North Atlantic. This interpretation is supported by results of Iudicone et al. (2008b) showing that SAMW formation by air-sea buoyancy fluxes is largely compensated by interior mixing. Both Marsh et al. (2000) and Sloyan and Rintoul (2001b) show that interior mixing plays a role comparable to air-sea buoyancy fluxes in SAMW formation. Downes et al. (2011) show that about half of SAMW that subducts in the ocean interior is converted into adjacent water masses. An alternative interpretation is that water in the SAMW density range formed through air-sea fluxes is mostly transported northward out of the Southern Ocean, while regional diapycnal mixing creates the net volume loss for these two years. In other words, the volume decrease is so large over the two years that it is difficult to anticipate the relative reduction in northward export versus the diagnosed diapycnal flux if enough years were available to produce a more stationary average.

It is possible that the partial cancellation of formation/ destruction of water by air-sea flux and interior mixing obtained in SOSE might be a consequence of the indirect calculation of the mixing component. Currently, there are few studies that directly diagnose the transformation rates resulting from diapycnal mixing. The exceptions are studies by Garrett et al. (1995), Badin et al. (2010), Marshall et al. (1999), and Iudicone et al. (2008b). In a semianalytical study of Phillip's Red Sea Model, Garrett et al. (1995) suggested that there is no simple relationship between surface transformation $A$ and transformation resulting from interior mixing $\partial D / \partial \sigma$ of Eq. (2). Badin et al. (2010) observed a lack of relationship between the effect of air-sea fluxes and diffusive mixing on the formation rates in a one-dimensional model of a tidal front and in observations of transformation across a shelf break.

Zonal advective exchanges between the ocean basins follow the pattern of dominant SAMWs: the highest eastward transport is from the Indian to the Pacific, associated with strong SEISAMW production in the Indian, the second highest is from the Pacific to the Atlantic, incorporating the strong SEPSAMW production at a higher density than SEISAMW, and the weakest is from the Atlantic to the Indian. Each ocean basin has net meridional/zonal advective export in its own narrow SAMW density range, even though over the entire density range considered $\left(26.5<\sigma_{\theta}<27.1 \mathrm{~kg} \mathrm{~m}^{-3}\right)$, only the Indian Ocean has a net export. Water formed in the Indian Ocean in the broad SAMW density range that is transported to Pacific is destroyed there both by air-sea buoyancy fluxes $(-1.1,-4.6) \mathrm{Sv}$ and diapycnal mixing $(-5.6,-8.4) \mathrm{Sv}$.

Air-sea flux formation rates peak at the SEISAMW and SEPSAMW densities: these are also the dominant SAMWs in terms of low PV on isopycnals. Formation is due equally to heat and freshwater processes. Integrated globally over the Southern Ocean, SEISAMW $(26.75<$ $\sigma_{\theta}<26.85 \mathrm{~kg} \mathrm{~m}^{-3}$ ) is formed from both lighter water (by air-sea heat loss) and denser water (by air-sea heat gain and freshening). Water in the SEPSAMW density range $\left(26.95<\sigma_{\theta}<27.05 \mathrm{~kg} \mathrm{~m}^{-3}\right)$ is formed globally from denser water (by freshening) and considerably less from lighter water (by air-sea heat loss). However, within the regions of their strongest mode water signatures, that is, the lowest PV on isopycnals and deepest winter mixed layers, both SEISAMW and SEPSAMW are formed from lighter water through buoyancy (heat) loss.

The enhanced volume loss over these two years in the SEISAMW and SEPSAMW low PV pools suggests that formation in these regions was not as vigorous in these two years as over the longer term. The southern annular mode index reached a relative decadal low in 2005 and 2006, compared with a high achieved in the late 1990s; a high southern annular mode index has been shown to coincide with increased Southern Hemisphere subtropical gyre circulation, which carries SEISAMW and SEPSAMW more rapidly into the subtropical gyres (McDonagh et al. 2005; Roemmich et al. 2009) Until a longer time series is available, we cannot draw quantitative conclusions about the importance of formation of low PV SAMW by cooling of less dense, upstream SAMWs relative to formation throughout the circumpolar 
a) Year 2005: Transformation (Sv)

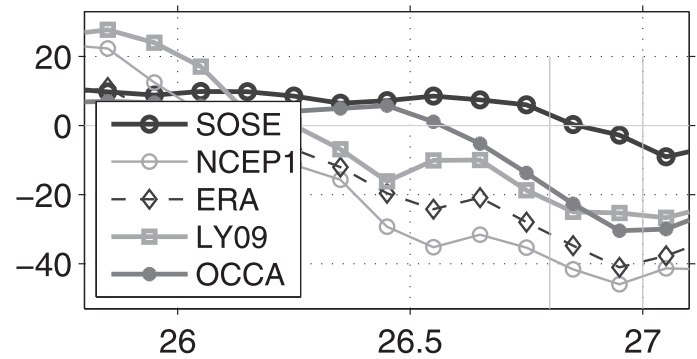

c) Year 2006: Transformation (Sv)

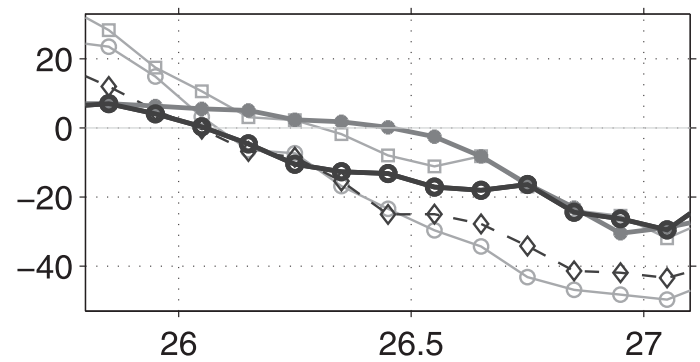

e) Time-average: Transformation (Sv)

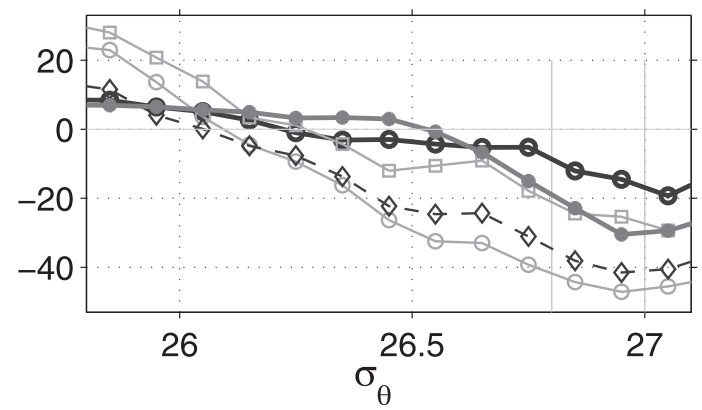

b) Formation

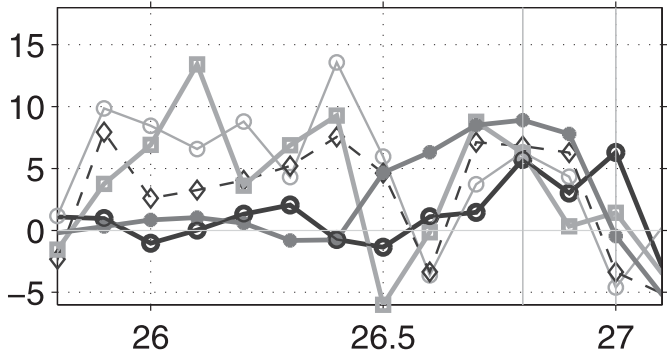

d)

Formation

(Sv)

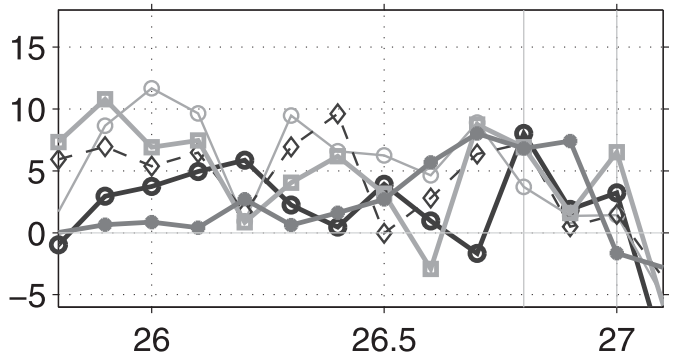

f) Formation (Sv)

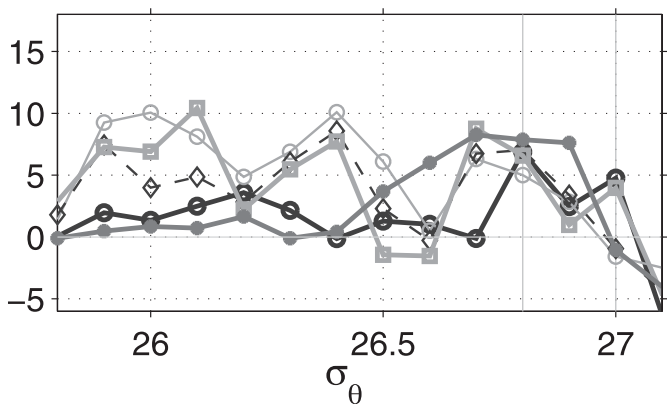

FIG. A1. (left) Transformation and (right) formation rates (Sv) as in Fig. 8, but based on NCEP1, ERA-Interim, LY09, and OCCA buoyancy heat equivalent flux and sea surface density, each estimated using five-day averages and subsequently averaged over year (left) 2005 and (right) 2006. SOSE and OCCA provide all the variables, including sea surface salinity, needed to estimate the air-sea buoyancy flux. For NCEP1 and ERA-Interim, sea surface salinity from the NCEP Global Ocean Data Assimilation System was used. For LY09, sea surface salinity from the Polar Science Center Hydrographic Climatology (PHC2) was used (see the appendix).

outcrop from upwelling of denser water that gains buoyancy from air-sea fluxes.

Acknowledgments. This work was supported by NSF Ocean Sciences Grants OCE-0327544 and OCE-0850869 to Scripps Institution of Oceanography. NCEP Reanalysis data are provided by the NOAA/OAR/ESRL PSD, Boulder, Colorado, from their web site (http://www.cdc. noaa.gov/). The fields that are used in this study are ERAInterim (dataset number ds627.0), GODAS (dataset number ds277.6), and LY09 (listed as Coare2.0 Global air-sea flux dataset, dataset number ds260.2). They were downloaded from the Research Data Archive (RDA), (http://dss.ucar.edu), which is maintained by the Computational and Information Systems Laboratory
(CISL) at the National Center for Atmospheric Research (NCAR). NCAR is sponsored by the National Science Foundation (NSF).

\section{APPENDIX}

\section{Walin SAMW Surface Formation Rates Using Other Air-Sea Buoyancy Flux Products}

How sensitive are the SOSE Walin formation rate estimates to the specific air-sea flux dataset that is used, given that commonly used flux products differ so much in the poorly sampled Southern Ocean? In Cerovečki et al. (2011) we compared the SOSE air-sea buoyancy fluxes with NCEP1, the ERA-Interim, and LY09. 
TABLE A1. Densities $\sigma_{\theta}$ (center of $0.1 \sigma_{\theta}$ interval is listed) and global formation rate $(\mathcal{F} \mathcal{R}$ ) estimates (Sv), given by Eq. (5), of SEISAMW and SEPSAMW from Walin analysis for years 2005 and 2006 using various air-sea flux products, also shown in Figs. A1c,d.

\begin{tabular}{lcccc}
\hline \hline & SEISAMW: $\sigma_{\theta}$ and $\mathcal{F} \mathcal{R}$, & SEPSAMW: $\sigma_{\theta}$ and $\mathcal{F} \mathcal{R}$, & SEISAMW: $\sigma_{\theta}$ and $\mathcal{F} \mathcal{R}$, & $\begin{array}{c}\text { SEPSAMW: } \sigma_{\theta} \text { and } \mathcal{F} \mathcal{R}, \\
\text { yata source }\end{array}$ \\
year 2005 & year 2005 & year 2006 & 2006 \\
\hline SOSE & 26.8 and $5.6 \mathrm{~Sv}$ & 27.0 and $6.3 \mathrm{~Sv}$ & 26.8 and $8.2 \mathrm{~Sv}$ & $27.0 \mathrm{and} 3.2 \mathrm{~Sv}$ \\
NCEP1 & 26.8 and $6.2 \mathrm{~Sv}$ & 26.9 and $4.2 \mathrm{~Sv}$ & 26.7 and $8.9 \mathrm{~Sv}$ & $27.0 \mathrm{and} 1.4 \mathrm{~Sv}$ \\
ERA-Interim & 26.7 and $6.9 \mathrm{~Sv}$ & 27.0 and $6.2 \mathrm{~Sv}$ & 26.8 and $7.2 \mathrm{~Sv}$ & $27.0 \mathrm{and} 1.6 \mathrm{~Sv}$ \\
LY09 & 26.7 and $8.8 \mathrm{~Sv}$ & 27.0 and $1.4 \mathrm{~Sv}$ & 26.7 and $8.7 \mathrm{~Sv}$ & $27.0 \mathrm{and} 6.5 \mathrm{~Sv}$ \\
OCCA & 26.8 and $8.9 \mathrm{~Sv}$ & 26.9 and $7.8 \mathrm{~Sv}$ & 26.7 and $8.0 \mathrm{~Sv}$ & 26.9 and $7.4 \mathrm{~Sv}$ \\
\hline
\end{tabular}

Here we calculate SAMW formation rates from each of these products, and also from the OCCA state estimate that is used to constrain the initial and northern boundary conditions in SOSE (Fig. A1).

SOSE and OCCA provide all of the variables needed to estimate the air-sea buoyancy flux, but sea surface salinity must be obtained externally for the freshwater fluxes for NCEP1, ERA-Interim, and LY09. For NCEP1 and ERA-Interim we used sea surface salinity from the NCEP Global Ocean Data Assimilation System (GODAS) (Behringer and Xue 2004). For LY09, we used sea surface salinity from the Polar Science Center Hydrographic Climatology (PHC2), which is a blending of the Levitus et al. (1998) and Steele et al. (2001) datasets, following Danabasoglu et al. (2009) and S. Griffies (2012, personal communication). Sea surface temperature for LY09 was also required and was taken from the Hadley Centre sea surface temperature (Rayner et al. 2003).

We focus on the formation peaks that occur in the SEISAMW and SEPSAMW density ranges (Fig. A1; Table A1). The SEISAMW formation rate estimates obtained from the various products differ less than those of SEPSAMW. Overall, averaged over all five products and both years, the SEISAMW formation rate was $(7.3,8.2) \mathrm{Sv}$ and SEPSAMW formation was (5.2, 4.0) Sv. SOSE taken by itself, averaged over both years, yields $(5.8,8.0)$ Sv of SEISAMW and $(6.3,3.2)$ Sv of SEPSAMW, clearly within the range of the whole group of products.

SOSE yields two distinct peaks in water mass formation at the SEISAMW and SEPSAMW densities that are inferred from the low PV distribution (section 3 and historically). LY09 also yields two distinct formation peaks for SEISAMW and SEPSAMW, but the SEISAMW peak is at somewhat lower density $\left(\sigma_{\theta}=26.7 \mathrm{~kg} \mathrm{~m}^{-3}\right)$ than the observed mode water. Formation rate estimates obtained from the other air-sea buoyancy flux products yield a wide peak in water mass formation spanning the whole SAMW density range, with no differentiation between SEISAMW and SEPSAMW (Fig. A1), which is unphysically coarse given the clearly separate SEISAMW and SEPSAMW signals in PV.

\section{REFERENCES}

Badin, G., and R. G. Williams, 2010: On the buoyancy forcing and residual circulation in the Southern Ocean: The feedback from Ekman and eddy transfer. J. Phys. Oceanogr., 40, 295-310.

,$- \ldots$, and J. Sharples, 2010: Water-mass transformation in the shelf seas. J. Mar. Res., 68, 1989-2010.

Behringer, D. W., and Y. Xue, 2004: Evaluation of the global ocean data assimilation system at NCEP: The Pacific Ocean. Preprints, Eighth Symp. on Integrated Observing and Assimilation Systems for Atmosphere, Oceans, and Land Surface, Seattle, WA, Amer. Meteor. Soc., P2.3. [Available online at https://ams. confex.com/ams/84Annual/webprogram/Paper70720.html.]

Bourassa, M. A., and Coauthors, 2013: High-latitude ocean and sea-ice surface fluxes: Challenges for climate research. Bull. Amer. Meteor. Soc., 94, 403-423.

Brambilla, E., L. D. Talley, and P. E. Robbins, 2008: Subpolar mode water in the northeastern Atlantic: 2. Origin and transformation. J. Geophys. Res., 113, C04026, doi:10.1029/ 2006JC004063.

Cerovečki, I., and J. Marshall, 2008: Eddy modulation of air-sea interaction and convection. J. Phys. Oceanogr., 38, 65-83.

_, L. Talley, and M. Mazloff, 2011: Southern Ocean air-sea buoyancy flux estimates. J. Climate, 24, 6283-6306.

Danabasoglu, G., S. Peacock, K. Lindsay, and D. Tsumune, 2009: Sensitivity of CFC-11 uptake to physical initial conditions and interannually varying surface forcing in a global ocean model. Ocean Modell., 29, 58-65.

Dong, S., J. Sprintall, S. T. Gille, and L. Talley, 2008: Southern Ocean mixed-layer depth from Argo float profiles. J. Geophys. Res., 113, C06013, doi:10.1029/2006JC004051.

Downes, S. M., A. Gnanadesikan, S. M. Griffies, and J. L. Sarmiento, 2011: Water mass exchange in the Southern Ocean in coupled climate models. J. Phys. Oceanogr., 41, 1756-1771.

Fine, R. A., 1993: Circulation of Antarctic Intermediate Water in the Indian Ocean. Deep-Sea Res., 40, 2021-2042.

Forget, G., 2010: Mapping ocean observations in a dynamical framework: A 2004-2006 ocean atlas. J. Phys. Oceanogr., 40, 1201-1221.

Garrett, C., K. Speer, and E. Tragou, 1995: The relationship between water mass formation and the surface buoyancy flux, with application to Phillips' Red Sea model. J. Phys. Oceanogr., 25, 1696-1705.

Gill, A. E., 1982: Atmosphere-Ocean Dynamics. Academic Press, $662 \mathrm{pp}$. 
Hallberg, R., and A. Gnanadesikan, 2006: The role of eddies in determining the structure and response of the wind-driven Southern Hemisphere overturning: Results from the Modeling Eddies in the Southern Ocean (MESO) project. J. Phys. Oceanogr., 36, 2232-2252.

Hanawa, K., and L. D. Talley, 2001: Mode waters. Ocean Circulation and Climate, G. Siedler, J. Church, and J. Gould, Eds., International Geophysics Series, Vol. 77. Academic Press, 373-386.

Hasson, A., A. Koch-Larrouy, R. Morrow, M. Juza, and T. Penduff, 2012: The origin and fate of mode water in the Southern Pacific Ocean. Ocean Dyn., 62, 335-354, doi:10.1007/s10236-011-0507-3.

Heywood, K. J., A. C. Naveira Garabato, and D. P. Stevens, 2002: High mixing rates in the abyssal Southern Ocean. Nature, 415, 1011-1014.

Holte, J. W., 2010: Subantarctic Mode Water formation: Air-sea fluxes and cross-frontal exchange. Ph.D. dissertation, University of California, San Diego, 112 pp.

—, L. D. Talley, T. K. Chereskin, and B. M. Sloyan, 2012: The role of air-sea fluxes in Subantarctic Mode Water formation. J. Geophys. Res., 117, C03040, doi:10.1029/2011JC007798.

$-, \ldots, \ldots$, and -2013 : Subantarctic mode water in the southeast Pacific: Effect of exchange across the Subantarctic Front. J. Geophys. Res., 118, 2052-2066, doi:10.1002/jgrc.20144.

Ito, T., M. Woloszyn, and M. Mazloff, 2010: Anthropogenic carbon dioxide transport in the Southern Ocean driven by Ekman flow. Nature, 463, 80-83.

Iudicone, D., G. Madec, B. Blanke, and S. Speich, 2008a: The role of Southern Ocean surface forcings and mixing in the global conveyor. J. Phys. Oceanogr., 38, 1377-1400.

,-- , and T. J. McDougall, 2008b: Water-mass transformations in a neutral density framework and the key role of light penetration. J. Phys. Oceanogr., 38, 1357-1376.

- S. Speich, G. Madec, and B. Blanke, 2008c: The global conveyor belt from a Southern Ocean perspective. J. Phys. Oceanogr., 38, 1401-1425.

Kalnay, E., and Coauthors, 1996: The NCEP/NCAR 40-Year Reanalysis Project. Bull. Amer. Meteor. Soc., 77, 437-471.

Karsten, R., and J. Marshall, 2002: Constructing the residual circulation of the Antarctic Circumpolar Current from observations. J. Phys. Oceanogr., 32, 3315-3327.

Karstensen, J., and D. Quadfasel, 2002: Formation of Southern Hemisphere thermocline waters: Water mass conversion and subduction. J. Phys. Oceanogr., 32, 3020-3038.

Koch-Larrouy, A., R. Morrow, T. Penduff, and M. Juza, 2010: Origin and mechanism of Subantarctic Mode Water formation and transformation in the Southern Indian Ocean. Ocean Dyn., 60, 563-583.

Large, W. G., and S. Pond, 1981: Open ocean momentum flux measurements in moderate to strong winds. J. Phys. Oceanogr., 11, 324-336.

_ formation. Ocean Circulation and Climate, G. Siedler, J. Church, and J. Gould, Eds., International Geophysics Series, Vol. 77. Academic Press, 317-336.

— ually varying air-sea flux data set. Climate Dyn., 33, 341-364.

Levitus, S., T. P. Boyer, M. E. Conkright, T. O'Brien, J. Antonov, C. Stephens, L. Stathoplos, D. Johnson, and R. Gelfeld, 1998: Introduction. Vol. 1, World Ocean Database 1998, NOAA Atlas NESDIS 18, 346 pp.

Macdonald, A. M., and C. Wunsch, 1996: An estimate of global ocean circulation and heat fluxes. Nature, 382, 436-439.
Marsh, R., G. A. J. Nurser, A. P. Megann, and A. L. New, 2000: Water mass transformation in the Southern Ocean of a global isopycnal coordinate GCM. J. Phys. Oceanogr., 30, 1013-1045.

Marshall, J., D. Jamous, and J. Nilsson, 1999: Reconciling thermodynamic and dynamic methods of computation of watermass transformation rates. Deep-Sea Res., 46, 545-572.

Maze, G., G. Forget, M. Buckley, J. Marshall, and I. Cerovečki, 2009: Using transformation and formation maps to study the role of air-sea heat fluxes in North Atlantic eighteen degree water formation. J. Phys. Oceanogr., 39, 1818-1835.

Mazloff, M. R., P. Heimbach, and C. Wunsch, 2010: An eddypermitting Southern Ocean state estimate. J. Phys. Oceanogr. 40, 880-899.

McCarthy, M. C., and L. D. Talley, 1999: Three-dimensional potential vorticity structure in the Indian Ocean. J. Geophys. Res., 104 (C6), 13 251-13 267.

McCartney, M. S., 1977: Subantarctic Mode Water. A Voyage of Discovery: George Deacon 70th Anniversary Volume, M. V. Angel, Ed., Pergamon Press, 103-119.

_ 1982: The subtropical recirculation of Mode Waters. J. Mar. Res., 40 (Suppl.), 427-464.

McDonagh, E. L., H. L. Bryden, B. A. King, R. J. Sanders, S. A. Cunningham, and R. Marsh, 2005: Decadal changes in the South Indian Ocean thermocline. J. Climate, 18, 1575-1590.

Moore, G. W. K., and I. A. Renfrew, 2002: An assessment of the surface turbulent heat fluxes from the NCEP reanalysis over western boundary currents. J. Climate, 15, 2020-2037.

Naveira Garabato, A. C., D. P. Stevens, and K. J. Heywood, 2003: Water mass conversion, fluxes, and mixing in the Scotia Sea diagnosed by an inverse model. J. Phys. Oceanogr., 33, 2565-2587.

_ , K. L. Polzin, B. A. King, K. J. Heywood, and M. Visbeck, 2004: Widespread intense turbulent mixing in the Southern Ocean. Science, 303, 210-213.

—, D. P. Stevens, A. J. Watson, and W. Roether, 2007: Shortcircuiting of the overturning circulation in the Antarctic Circumpolar Current. Nature, 447, 194-197.

Nurser, A. J. G., R. Marsh, and R. G. Williams, 1999: Diagnosing water mass formation from air-sea fluxes and surface mixing. J. Phys. Oceanogr., 29, 1468-1487.

Orsi, A. H., T. Whitworth III, and W. D. Nowlin Jr., 1995: On the meridional extent and fronts of the Antarctic Circumpolar Current. Deep-Sea Res., 42, 641-673.

Piola, A. R., and D. T. Georgi, 1982: Circumpolar properties of Antarctic intermediate water and Subantarctic Mode Water. Deep Sea Res., 29, 687-711.

Provost, C., C. Escoffier, K. Maamaatuaiahutapu, A. Kartavtseff, and V. Garcon, 1999: Subtropical mode waters in the South Atlantic Ocean. J. Geophys. Res., 104, 21 033-21 049.

Rayner, N. A., D. E. Parker, E. B. Horton, C. K. Folland, L. V. Alexander, D. P. Rowell, E. C. Kent, and A. Kaplan, 2003: Global analyses of sea surface temperature, sea ice, and night marine air temperature since the late nineteenth century. J. Geophys. Res., 108, 4407, doi:10.1029/2002JD002670.

Rintoul, S. R., 1991: South Atlantic interbasin exchange. J. Geophys. Res., 96, 2675-2692.

— C. Hughes, and D. Olbers, 2001: The Antarctic Circumpolar Current System. Ocean Circulation and Climate, G. Siedler, J. Church, and J. Gould, Eds., International Geophysics Series, Vol. 77. Academic Press, 271-302.

Roemmich, D., and B. Cornuelle, 1992: Observing the fluctuations of gyre-scale ocean circulation: A study of the subtropical South Pacific. J. Phys. Oceanogr., 20, 1919-1934. 
_ J. Jilson, R. Davis, P. Sutton, S. Wijffels, and S. Rintoul, 2009: Decadal spinup of the South Pacific subtropical gyre. J. Phys. Oceanogr., 37, 162-173.

Sabine, C. L., and Coauthors, 2004: The oceanic sink for anthropogenic $\mathrm{CO}_{2}$. Science, 305, 367-371.

Sallee, J. B., K. Speer, S. Rintoul, and S. Wijffels, 2010: Southern Ocean thermocline ventilation. J. Phys. Oceanogr., 40, 509529.

Schmitz, W. J., 1996: On the World Ocean circulation. Vol. II: The Pacific and Indian Oceans-A global update. Woods Hole Oceanographic Institute Tech. Rep. WHOI-96-08, 241 pp.

Sloyan, B. M., and S. R. Rintoul, 2001a: The Southern Ocean limb of the global deep overturning circulation. J. Phys. Oceanogr., 31, 143-173.

— , and 2001b: Circulation, renewal and modification of Antarctic mode and intermediate water. J. Phys. Oceanogr., 31, 1005-1030.

_ , and I. V. Kamenkovich, 2007: Simulation of Subantarctic Mode and Antarctic Intermediate Waters in climate models. J. Climate, 20, 5061-5080.

—, L. D. Talley, T. Chereskin, R. Fine, and J. Holte, 2010: Antarctic Intermediate water and Subantarctic Mode water formation in the southeast Pacific: The role of turbulent mixing. J. Phys. Oceanogr., 40, 1558-1574.

Speer, K., and E. Tziperman, 1992: Rates of water mass formation in the North Atlantic Ocean.J. Phys. Oceanogr., 22, 93-104.

—, H.-J. Isemer, and A. Biastoch, 1995: Global water mass formation from revised COADS data. J. Phys. Oceanogr., 25, 2444-2457.

— S. Rintoul, and B. Sloyan, 2000: The diabatic Deacon cell. J. Phys. Oceanogr., 30, 3212-3222.

Spence, P., O. A. Saenko, M. Eby, and A. J. Weaver, 2009: The Southern Ocean overturning: Parameterized versus permitted eddies. J. Phys. Oceanogr., 39, 1634-1651.

St. Laurent, L., A. C. Naveira Garabato, J. R. Ledwell, A. M. Thurnherr, J. M. Toole, and A. J. Watson, 2012: Turbulence and diapycnal mixing in Drake Passage. J. Phys. Oceanogr., 42, 2143-2152.

Stammer, D., K. Ueyoshi, A. Kohl, W. G. Large, S. A. Josey, and C. Wunsch, 2004: Estimating air-sea fluxes of heat, freshwater, and momentum through global ocean data assimilation. J. Geophys. Res., 109, C05023, doi:10.1029/2003JC002082.

Steele, M., R. Morley, and W. Ermold, 2001: PHC: A global ocean hydrography with a high quality Arctic Ocean. J. Climate, 14, 2079-2087.

Talley, L. D., 1996: Antarctic Intermediate Water in the South Atlantic. The South Atlantic: Present and Past Circulation, G. Wefer et al., Eds., Springer-Verlag, 219-238.

- 1999: Some aspects of ocean heat transport by the shallow, intermediate and deep overturning circulations. Mechanisms of Global Climate Change at Millennial Time Scales, Geophys. Monogr., Vol. 112, Amer. Geophys. Union, 1-22.
— 2003: Shallow, intermediate, and deep over- turning components of the global heat budget. J. Phys. Oceanogr., 33, 530560 .

- 2007: Hydrographic Atlas of the World Ocean Circulation Experiment (WOCE). Volume 2: Pacific Ocean. M. Sparrow, P. Chapman, and J. Gould, Eds., International WOCE Project Office, $327 \mathrm{pp}$.

- 2008: Freshwater transport estimates and the global overturning circulation: Shallow, deep and throughflow components. Prog. Oceanogr., 78, 257-303, doi:10.1016/j.pocean.2008.05.001.

_ J. L. Reid, and P. E. Robbins, 2003: Data-based meridional overturning streamfunctions for the global ocean. J. Climate, 16, 3213-3226.

, T. Chereskin, J. Holte, and Y.-D. Lenn, 2006: Subantarctic Mode Water and Antarctic Intermediate Water formation near the Subantarctic Front in the southeast Pacific in winter 2005. Ocean Sci., Abstract OS075.

Taylor, P. K., Ed., 2000: Intercomparison and validation of oceanatmosphere energy flux fields-Final report of the Joint WCRP/SCOR Working Group on air-sea fluxes. WCRP Rep. WCRP-112, WMO/TD-1036, 306 pp.

Thompson, R. O., and R. J. Edwards, 1981: Mixing and water mass formation in the Australian Subantarctic. J. Phys. Oceanogr., 11, 1399-1406.

Tsuchiya, M., and L. D. Talley, 1998: A Pacific hydrographic section at $88^{\circ} \mathrm{W}$ : Water property distribution. J. Geophys. Res., 103 (C6), 12 899-12 918.

—,- , and M. S. McCartney, 1994: Water mass distributions in the western Atlantic: A section from South Georgia Island $\left(54^{\circ} \mathrm{S}\right)$ northward across the equator. J. Mar. Res., 52, 55-81.

Tziperman, E., 1986: On the role of interior mixing and air-sea fluxes in determining the stratification and circulation of the oceans. J. Phys. Oceanogr., 16, 680-693.

Walin, G., 1982: On the relation between sea-surface heat flow and thermal circulation in the ocean. Tellus, 34, 187-195.

Warren, B. A., J. H. LaCasce, and P. E. Robbins, 1996: On the obscurantist physics of "form drag" in theorizing about the Circumpolar Current. J. Phys. Oceanogr., 26, 2297-2301.

Waterman, S., A. C. Naveira Garabato, and K. L. Polzin, 2013: Internal waves and turbulence in the Antarctic Circumpolar Current. J. Phys. Oceanogr., 43, 259-282.

Willey, D. A., R. A. Fine, R. E. Sonnerup, J. L. Bullister, W. M. Smethie, and M. J. Warner, 2004: Global oceanic chlorofluorocarbon inventory. Geophys. Res. Lett., 31, L01303, doi:10.1029/2003GL018816.

Wong, A. P. S., 2005: Subantarctic mode water and Antarctic intermediate water in the South Indian Ocean based on profiling float data 2000-2004. J. Mar. Res., 63, 789-812.

Wunsch, C., and P. Heimbach, 2007: Practical global ocean state estimation. Physica D, 230, 197-208, doi:10.1016/j.physd.2006.09.040.

Zhang, H.-M., and L. D. Talley, 1998: Heat and buoyancy budgets and mixing rates in the upper thermocline of the Indian and Global Oceans. J. Phys. Oceanogr., 28, 1961-1978. 